NBER WORKING PAPER SERIES

\title{
THE EFFECT OF PRESCRIPTION DRUG MONITORING PROGRAMS ON OPIOID UTILIZATION IN MEDICARE
}

\author{
Thomas C. Buchmueller \\ Colleen Carey \\ Working Paper 23148 \\ http://www.nber.org/papers/w23148 \\ NATIONAL BUREAU OF ECONOMIC RESEARCH \\ 1050 Massachusetts Avenue \\ Cambridge, MA 02138 \\ February 2017
}

This research was supported by the Robert Wood Johnson Foundation Scholars in Health Policy Research Program. Anup Das provided excellent research assistance. The authors thank Jean Abraham, Melinda Beeuwkes Buntin, and seminar participants at Cornell University, the Midwestern Health Economic Conference, and the 2016 Association for Public Policy Analysis and Management Annual Meeting. The views expressed herein are those of the authors and do not necessarily reflect the views of the National Bureau of Economic Research.

NBER working papers are circulated for discussion and comment purposes. They have not been peer-reviewed or been subject to the review by the NBER Board of Directors that accompanies official NBER publications.

(C) 2017 by Thomas C. Buchmueller and Colleen Carey. All rights reserved. Short sections of text, not to exceed two paragraphs, may be quoted without explicit permission provided that full credit, including $\odot$ notice, is given to the source. 
The Effect of Prescription Drug Monitoring Programs on Opioid Utilization in Medicare Thomas C. Buchmueller and Colleen Carey

NBER Working Paper No. 23148

February 2017

JEL No. I12,I18

\begin{abstract}
$\underline{\text { ABSTRACT }}$
The misuse of prescription opioids has become a serious epidemic in the US. In response, states have implemented Prescription Drug Monitoring Programs (PDMPs), which record a patient's opioid prescribing history. While few providers participated in early systems, states have recently begun to require providers to access the PDMP under certain circumstances. We find that "must access" PDMPs significantly reduce measures of misuse in Medicare Part D. In contrast, we find that PDMPs without such provisions have no effect. We find stronger effects when providers are required to access the PDMP under broad circumstances, not only when they are suspicious.
\end{abstract}

Thomas C. Buchmueller

Stephen M. Ross School of Business

University of Michigan

701 Tappan

Ann Arbor, MI 48109

and NBER

tbuch@umich.edu

Colleen Carey

298 Martha van Rensselaer Hall

Ithaca, NY 14850

cmc528@cornell.edu 


\section{Introduction}

In recent years, the use of prescription opioids has grown dramatically in the United States; between 1999 and 2010, opioid prescriptions increased by 300\% (Kunins et al., 2013). Opioids are an effective analgesic, but bring a high risk of addiction and overdose, and over the same period deaths from opioid poisoning more than quadrupled (Chen et al. 2014). Increases in opioid overdose deaths contributed to a historical reversal in the decline of mid-life all-cause mortality over the period 1999 to 2013 (Case and Deaton, 2015). In addition, it became clear that opioids prescribed legitimately by well-meaning medical professionals were being diverted to street sale for non-medical use (Dart et al., 2015). In October 2015, President Obama and health care provider groups announced a set of joint public-private initiatives aiming to improve prescribing practices and expand addiction treatment; the bipartisan $21^{\text {st }}$ Century Cures Act awards more than $\$ 1$ billion in new funding for grants to states for related efforts.

The most significant policy responses to the opioid problem have taken place at the state level. Most importantly, nearly every state has implemented a Prescription Drug Monitoring Program, or PDMP, that collects data on prescriptions for controlled substances to facilitate detection of suspicious prescribing and utilization. A PDMP allows authorized individuals to view a patient's prescribing history in order to identify those who are misusing or diverting opioids. State programs have evolved over time and continue to vary along several dimensions, including the extent to which medical providers are encouraged to access the data. Early programs were developed by law enforcement agencies and had provisions that made it difficult for providers to access the data. Other programs did not block provider access, but did not actively encourage them to utilize the data. PDMP administrative data show that, when provider access is possible but not mandatory, only a small share of providers create PDMP logins and actually request patient histories $(\mathrm{PDMP}$ Center of Excellence, 2014). A goal of the October 2015 initiative was to "double the number of health care providers registered with their state PDMPs in the next two years", showing the recent acknowledgment of this problem (White House, 2015). Low provider utilization of these programs may explain why a number of studies find that PDMPs have little or no effect on opioid use and related adverse health outcomes (Meara et al., 2016, Paulozzi et al., 2011, Reifler et al., 2012, Jena et al., 2014, Li et al., 2014, Brady et al., 2014, Haegerich et al., 2014).

Between 2007 and 2013, seventeen states implemented PDMPs for the first time but did not require providers to access them. Ten states enacted stronger laws requiring providers to access the PDMP under certain circumstances prior to prescribing. In nine of these ten states the "must access" requirement was enacted to improve the efficacy of a PDMP that was already in place. Prior studies fail to account for differences between programs that do and do not require providers to access the database. This requirement 
is the main focus of this paper. Applying difference-in-differences models to aggregated claims data from Medicare's prescription drug program (Medicare Part D), we evaluate the effect of PDMPs on the prescription drug utilization of Medicare beneficiaries. Our large-N microdata allows us to go beyond measures of average utilization, which have been the main focus of previous studies, to measure rare outcomes in the upper tail of the distribution - the exact outcomes that PDMPs are meant to impede. For example, a key outcome that we analyze is the percentage of opioid users who obtain prescriptions from five or more prescribers, which is a commonly used marker for "doctor shopping". The Part D claims also allow us to construct multiple measures capturing the intensity of opioid utilization. Additional data on hospital, outpatient, and physician claims provide information on opioid poisoning incidents. Effects among the Medicare population are likely to correlate with effects among the general population, and due to the program's size effects in Medicare are noteworthy in their own right. Meara et al. (2016) note that nearly one in four prescription overdose deaths in 2008 was a disabled Medicare beneficiary.

We first establish that a PDMP without a "must access" provision is not associated with opioid misuse in Medicare. In contrast, we find that implementing a "must access" PDMP reduces many of measures of excessive quantity - the share of beneficiaries obtaining more than seven months supply in each halfyear, and the share that fill claims before the previous claim's days supply has been used. In addition, we find that "must access" PDMPs reduce "shopping" behavior. In treatment states relative to controls, the percentage of Medicare Part D enrollees who obtain prescriptions from five or more prescribers falls by $8 \%$ and the percentage of enrollees who obtain prescriptions from five or more pharmacies by more than $15 \%$. These results suggest that measures that require prescribers to access the PDMP can be an effective way to reduce questionable opioid use patterns. And even though our quantity and shopping measures are strongly correlated with opioid poisoning incidents as observed in medical claims data, we find a negative but statistically insignificant relationship between "must access" PDMP laws and opioid poisoning incidents.

Because there is little or no integration of state databases, drug-seeking individuals trying to avoid scrutiny may cross state borders to escape detection by the PDMP in their home state. We test for such avoidance behavior using a novel measure of whether a Part D enrollee disproportionately obtains opioids from out-of-state prescribers or pharmacies (relative to her out-of-state rate for non-opioid prescriptions). Our results indicate that a "must access" PDMP in a given state raises the rate at which that state's residents obtain opioids from out-of-state prescribers by roughly a third of a standard deviation.

We also exploit the Medicare medical claims for a new measure of shopping behavior, also novel to our knowledge. An individual shopping for a provider willing to prescribe opioids will incur an unusual number of claims in which the provider bills Medicare for a "new patient" procedure code. A "must access" PDMP reduces the share of individuals with four or more new patient visits in a half-year by $15 \%$. Given Medicare 
outlays for these visits, a "must access" PDMP in every state would avert $\$ 174$ million in expenditures each half-year.

As is the case in many areas where public policies are enacted at the state level, there is some heterogeneity among "must access" PDMP laws. Although our main analysis estimates the average effect of these laws, we also estimate models that exploit this heterogeneity to compare what can plausibly be characterized as stronger or weaker forms of "must access". Specifically, we allow for differences among laws that pertain to certain care settings (2 states), laws that require providers to access the PDMP only when they are suspicious of an individual (3 states), and laws that effectively pertain to all providers and all patients ( 5 states). We find that the broadest laws, which apply to all ingredients and settings and do not rely on provider discretion, have the strongest impacts on our measures of excessive quantity. However, even the weaker laws have effects on measures of shopping behavior.

Additional results support a causal interpretation of our findings for "must access" laws. We estimate event-study regression models to test for differences in trends prior to the implementation of "must access" laws and generally find no statistically significant difference between "treatment" and "control" states in the pre period. We also investigate whether the estimated effects of "must access" PDMPs might be driven by other state policies, including either other aspects of PDMP design or non-PDMP opioid control policies. Based on an extensive review of state policies, we identified three policies that co-occur with our policy of interest, but these policies have little or no independent impact on opioid misuse and the estimated effects for "must access" laws are unchanged when we control for these alternative policies. We also show that our results are very robust to dropping any one of our treatment states, suggesting our findings are not driven by unusual circumstances in one of our implementing states. Finally, as a sort of placebo test, we examine the utilization of statins and antidepressants. It is very uncommon to obtain these drug classes from multiple prescribers or pharmacies, suggesting that our opioid "misuse" measures do not simply reflect poor care coordination among Medicare beneficiaries. We find no effects of a "must access" PDMP on the utilization of either of these two types of drugs.

Individuals who qualify for Medicare on the basis of a disability are known to have high rates of opioid misuse and abuse (GAO, 2011). We find that the majority of the policy impacts we find in the overall Medicare population are driven by the disabled subpopulation, particularly the low-income disabled. We also consider as a population of special interest all those who historically met our criteria for doctor-shopping at least once. Effects are quite large in percentage terms among this population, consistent with this policy curbing misuse among the targeted population.

With sizable financial support from the Federal government, every state but Missouri has implemented a PDMP in response to the prescription opioid epidemic. Our results help explain why the existing literature 
provides little consistent evidence of their effectiveness. Given that PDMPs are designed to combat the misuse and diversion of opioids by alerting providers of questionable utilization patterns, they will only be successful if providers make use of the data collected by the program. Based on this logic, in recent years states have begun strengthening their PDMPs by requiring providers to access the data. In this paper, we provide the first empirical evaluation of such "must access" laws.

\section{Background}

\subsection{Opioids and Medicare Part D}

In recent decades, many physicians have argued that pain, "the fifth vital sign", was historically undertreated (Pasero and McCaffery, 1997). In response, the medical community began to treat pain more aggressively, often using prescription opioids. The top panel of Figure 2 shows the spread in opioid prescriptions between 2007 and 2013, the time period covered by this analysis. Much of the increase came in prescriptions for chronic pain, despite the fact that research suggests that opioids are less effective for chronic pain than for acute pain, such as after surgery (Manchikanti et al., 2010). Along with the increase in utilization came significant increases in rates of misuse and overdose; the dashed line in Figure 2 shows a steep increase in emergency department visits for opioid poisoning. According to the National Survey on Drug Use and Health (NSDUH), by 2013 more than 35 million Americans had used pain relievers non-medically at least once in their life (NSDUH, 2014).

Given the significant disease burden of the elderly and disabled, it is not surprising that opioid use is quite common in Medicare Part D. The bottom half of Figure 2 depicts opioid utilization and poisonings among Part D enrollees, demonstrating the national trends are reproduced in the sample we consider. In 2010, approximately one-quarter of Part D enrollees took opioids (Jena et al., 2014). Use is especially prevalent among disabled Medicare beneficiaries: in 2011 nearly half filled an opioid prescription (Morden et al., 2014). Over the time period of this analysis, the median days supply among disabled opioid takers rose from 60 days in the first half of 2007 to 105 days in the second half of 2013. A 2011 report by the Government Accountability Office (GAO) found that in $20082 \%$ of Medicare beneficiaries obtained frequently-abused drugs (opioids as well as some stimulants and benzodiazepines) from five or more prescribers per year, which they deemed indicative of "doctor shopping" (GAO, 2011). Patterns of questionable access are more prevalent among the disabled, who comprise about a third of opioid takers in Medicare Part D. However, opioid misuse among the elderly has been rising in the very recent past. In 2012, the opioid mortality rate among those over sixty years of age surpassed that of those between twenty and fifty-nine (West et al., 2015).

For most years since the Medicare prescription drug program was established in 2006, program adminis- 
trators and plan sponsors have had a limited ability to identify or curtail opioid misuse (GAO, 2011). Efforts to address the problem have largely been limited to encouraging plans to "provide practitioner and beneficiary education as appropriate" when suspicious patterns were identified. While state Medicaid programs can require suspected opioid abusers to receive their drugs from only one prescriber or one pharmacy, the legislation authorizing Medicare Part D did not permit either Part D plans or the Center for Medicare and Medicaid Services (CMS) to restrict access in this way (GAO, 2011). In addition, while beneficiaries can change Part D plans at least yearly, an insurer that has identified suspected drug abuse was not permitted to transmit that information to future insurers (Blum, 2013). In July 2013, the last half-year of our sample, Medicare began notifying plans of individuals with potentially inappropriate opioid utilization as defined by its own PDMP-style Overutilization Monitoring System, although no action was required. In 2017 or 2018, CMS recommends that plans begin denying inappropriate claims at "point-of-sale", and plans will gain the authority to limit high-risk beneficiaries to certain prescribers or pharmacies (Agrawal, 2016). To note, opioids are relatively inexpensive, incurring a negotiated price of $\$ 1.61$ per day in our sample. Opioids account for only about $3 \%$ of Part D insurers' total drug costs in 2011, whereas antidepressants, for example, are taken by about as many individuals but account for nearly $10 \%$. If only a small portion of opioid utilization is inappropriate, insurers may not choose to undertake self-financed efforts to interdict it.

\subsection{State Prescription Drug Monitoring Programs}

The most important policies aimed at curbing opioid abuse are prescription drug monitoring programs, or PDMPs, which are established and operated by states to collect and facilitate the sharing of data on opioid prescriptions. The earliest programs were primarily designed to assist law enforcement in investigations, and were based around carbon copies. In the past decade, PDMPs have automated reporting, migrated online, and increased reporting frequency, meaning they now contain an up-to-date and complete patient prescription history. Policymakers have hypothesized that informing medical providers of potential misuse could help impede diversion and recreational use of opioids. A physician or pharmacist may agree to proceed if a prescribing history, such as in Figure 1 shows only a single prescriber, but might refuse if the history reflects multiple providers or an unusually large quantity of opioids.

However, even as information technology made it easier to obtain the data in a timely fashion, state programs established different rules regarding provider access. In some states, PDMPs began to allow providers to query the PDMP, while in others it was explicitly prohibited or allowed only for current (but not prospective) patients (Davis et al., 2014). Similarly, in some states, the PDMP actively generated reports to prescribers and pharmacies when a patient appeared to be misusing opioids; in other states, it was illegal for the PDMP to do so (Davis et al. 2014). 
Despite a growing recognition of the dangers of opioids, physician groups have not generally endorsed PDMP access as a solution. Physicians complained about interference with clinical practice, new paperwork burdens, and the difficulty of contextualizing and interpreting a prescribing history (Islam and McRae, 2014 Gourlay, 2013). When prescribers were allowed access, they were sometimes granted immunity from prosecution for not checking the PDMP (Davis et al., 2014). In this context, it is not surprising that when not mandated, only the most conscientious providers actively used the PDMP to inform prescribing decisions (Haffajee et al., 2015). For example, in the first year after a voluntary PDMP was established in Florida, a state with a well-publicized opioid misuse problem, fewer than 1 in 10 physicians had even created a login for the system (Poston, 2012). Similarly, two years after Rhode Island allowed prescribers to query its PDMP, officials estimated it was used in only $10 \%$ of prescriptions (Arditi, 2014). Levy et al. (2015) show that nearly half of prescriptions for opioids from the United States are written by primary care specialists, suggesting that even if the heaviest prescribers are enrolling, low rates of uptake will limit the effectiveness of PDMPs.

In recent years, a number of states have strengthened their PDMPs by requiring providers to access the data under certain circumstances. These "must access" provisions appear to have substantially increased provider take-up. When New York implemented a "must access" provision in 2013, the number of registrants increased fourteenfold, and the number of daily queries rose from fewer than 400 to more than 40,000. Similarly, in Kentucky, Tennessee and Ohio, implementing a "must access" provision increased by several orders of magnitude the number of providers registered and the number of queries received per day (PDMP Center of Excellence, 2014).

Table 1 summarizes state laws studied in this paper by providing, in the first two columns, the half-year that the state's original PDMP law went into effect and when a "must access" provision went into effect. Our main source of information on state laws is the detailed database of PDMPs collected by the Prescription Drug Abuse Policy System (pdaps.org). This database was created by multiple legally-trained researchers independently reviewing state laws relevant to PDMP operations for content and dates of enactment (Davis) et al. 2014). Note that we do not report laws for states whose first PDMP law passed before 2007, since they do not contribute to identification in later analyses. By the end of 2013, all states except Missouri and DC have passed some form of PDMP. In this paper we focus on the ten states that began to require providers (under certain circumstances) to access the PDMP prior to prescribing opioids. In all cases but one (Delaware) the "must access" provision strengthened an existing PDMP.

In our main analyses we treat all ten states that have a policy that requires providers to access the PDMP under certain circumstances as "must access" states, but in fact the laws do differ. In general, more recent "must access" policies are stronger than earlier laws. Louisiana's law applies only to pain clinics and Oklahoma's to methadone. In Nevada, Delaware, and Ohio providers must access the PDMP if they have 
"a reasonable belief that the patient may be seeking the controlled substance...for any reason other than the treatment of an existing medical condition." In 2012 or 2013, Kentucky, West Virginia, New Mexico, Tennessee and New York required access for all care settings and ingredients, and providers must check even if they are not suspicious. In Section 4.3 we explore how the impact of a "must access" provision varies by strength of the law.

Early studies on PDMPs generally did not attempt to distinguish among different types of programs. For example, Paulozzi et al. (2011) examine the relationship between whether a state has any kind of PDMP between 1999 and 2005 and opioid poisoning incidents and mortality. They find no effect. Similarly, using cross-sectional data from 2010, Jena et al. (2014) find no relationship between the presence of a state PDMP and the number of Medicare beneficiaries obtaining prescriptions from multiple providers. Reifler et al. (2012), considering 1999-2003, find that the growth in opioid use slows when states pass PDMP laws. Brady et al. (2014) and Li et al. (2014) find no effect on opioids dispensed or drug overdose mortality from PDMPs between 1999 and 2008. Meara et al. (2016) test the impact of PDMPs and a variety of other opioid interdiction policies in a difference-in-difference framework using disabled Medicare beneficiaries; they find no significant effects. In a review, Haegerich et al. (2014) conclude that 14 studies of PDMPs "have not clearly established significant effects on total opioid prescribing or health outcomes with PDMPs."

Two recent papers that are more optimistic about the effectiveness of PDMPs look more carefully, as we do, at PDMP characteristics. Patrick et al. (2016) find a greater impact on opioid overdose deaths in the general population in states whose PDMP monitors more drugs and updates data at least weekly. A study by Dowell et al. (2016) shares our focus on "must access" PDMP provisions; their results suggest that "must access" PDMPs are associated with a reduction in opioid overdose deaths and the morphine milligram equivalents of prescribed opioids per state resident. Neither of these recent papers examines the relationship between PDMPs and the type of extreme utilization that the programs are designed to reduce.

\section{Data and Methods}

\subsection{Measures of Opioid Use, Misuse, and Poisoning}

Our primary dataset is the prescription drug and medical claims of a random $5 \%$ subsample of Medicare beneficiaries enrolled in Part D and fee-for-service Medicare (not Medicare Advantage) in any year between 2007 and 2013. The prescription drug claims denote the exact drug purchased, days supply, purchase date, prescriber identifier and pharmacy identifier. Opioids are identified using the United States Pharmacopeia 2011 Medicare Model Guideline Formulary Reference File ${ }^{1}$ Because several of the legislative changes during

\footnotetext{
${ }^{1}$ We do not distinguish between Schedule II (most opioids) and Schedule III (hydrocodone combinations and buprenorphine) claims. Over our time period, all PDMPs covered Schedule II and nearly all covered Schedule III drugs (Davis et al. 2014).
} 
this period occurred in the middle of the calendar year, to better match the claims data to the appropriate policy regime, we divide the data into six-month periods, assigning laws to a period if they were in effect for more than half of the time.

Table 2 provides basic summary statistics for the full panel of FFS/Part D enrollees (first column) and the subsample with at least one opioid claim during each half-year (second column). For each of fourteen half-years, the sample size is approximately 950,000; individuals appear about eleven times. A quarter of the sample is entitled to Medicare due to disability and two in five are dually-eligible for Medicaid due to low wealth and income. In any half-year, $28 \%$ of FFS/Part D enrollees fill at least one prescription for opioids. Opioid takers are more likely than the average Part D enrollee to be eligible for Medicaid or disabled. Not surprisingly, opioid users also have higher rates of cancer and are more likely to be near the end of life $2^{2}$ We consider the full population of opioid takers, even though more than a third of these individuals fill only a single prescription (often as part of post-operative care).

Even with this rich detail, it is difficult to distinguish appropriate and inappropriate use of prescription opioids. We draw on prior research to construct several proxy measures of misuse. Table 3 describes the measures of opioid use and misuse that we construct using the claims data. We have three groups of outcomes: quantity-based outcomes, "shopping" outcomes, and medical service outcomes.

Our simplest quantity-based outcome is a measure of the share of Part D enrollees who take any opioids at all. However, our other quantity-based outcomes are intended to reflect the upper tail of the utilization distribution; the goal is to capture utilization patterns that previous research suggests are either indicative of misuse or dangerous per se. First, we create an indicator variable that equals one for all individuals who obtained 211 or more days supply (more than seven thirty-day prescriptions) of opioids in a half-year. The distribution of days supply is given in Figure 3 , with the right panel zooming in on the distribution above the cutoff. The right panels show the frequency of observations, revealing thousands of observations of even rare phenomena. Nearly $9 \%$ of opioid takers fill more than 210 days supply of opioid prescriptions in a half-year; high days supply could indicate abuse or opioid diversion, but could also result from patients experimenting with different ingredients or strengths, or combinations of long-acting and short-acting opioids.

The potential for mistaking these benign reasons for having high days supply can be reduced by converting each prescription to morphine-equivalent dosage (MED). The morphine-equivalent dosage allows opioids of different ingredients, strengths, and form (routes of administration) to be converted into equivalent milligrams of morphine ${ }^{3}$ We divide the total MED obtained in a six-month period by 180 days to create a "daily MED."

\footnotetext{
${ }^{2}$ Cancer identified by the ICD9 codes that comprise CMS Hierarchical Condition Codes 7, 8, 9, and 10 in any position in the inpatient, outpatient, and carrier (physician) medical claims. Cause of death is not noted in Medicare claims data.

${ }^{3}$ We collected the conversion of each opioid ingredient $\times$ strength $\times$ form from the following three sources: Palliative.org (2016); CMS (2015); Ohio Bureau of Workers' Compensation (2016). The exact conversion is available upon request.
} 
For example, hydrocodone has a morphine-equivalence factor of one; if an individual obtains an 18 day supply of 10mg of hydrocodone, he or she has obtained a "daily MED" of 1 over the half-year. Figure 4 depicts the distribution of this variable. The height of the first bar shows that more than three-quarters of opioid takers have less than ten MED over the six month period, most likely consistent with acute use over a limited period. $1.7 \%$ of opioid takers obtain enough opioids to have a continuous daily dosage of more than 120 MED. Guidelines for providers, e.g. Washington State Agency Medical Directors' Group (2010), suggest that chronic usage above this threshold is associated with an escalation in risk.

A final quantity-based measure is the prevalence of overlapping claims - i.e., having multiple prescriptions for the same drug at a point in time. We create a binary flag for whether an individual fills a second claim for the same ingredient more than a week before the first prescription should have been finished, based on its days supply $4^{4}$ If the two claims are for different ingredients, we attribute their overlap to the patient experimenting with other opioids and do not code the individual as having overlapping claims. This measure is similar to the concurrently supplied measure in previous research (Jena et al. 2014). More than 91\% of observations have no overlapping claims. Most of those with overlapping claims have only one, but individuals in the top percentile have six claims overlapping by more than a week in a six month period.

One of the main ways that a PDMP can reduce opioid abuse is by curtailing "shopping" behavior, whereby an individual visits multiple prescribers or pharmacies to obtain opioids. This outcome is of particular interest since the information provided by PDMPs is specifically designed to inform a provider of doctor shopping behavior. In the Part D claims, we can count the number of distinct providers from whom an enrollee received a prescription for opioids during the half-year and the number of different pharmacies at which opioid prescriptions were filled $[5$ For both variables, the modal value is one, though there is a long right tail, especially for the number of physicians. We construct a measure of doctor-shopping by identifying all Part D enrollees who received opioid prescriptions from five or more prescribers in a single period. In our data, $2.3 \%$ of opioid takers meet this criterion. It is possible that there are other explanations for a large number of prescribers, such as uncoordinated care. However, obtaining opioids from five or more prescribers is nine times as likely for opioids as it is for antidepressants, and more than 200 times as likely as it is for statins. We construct an analogous measure for individuals who fill opioid prescriptions at five or more pharmacies in a half-year. Seven of our ten implementing states require dispensers to check on the same grounds as prescribers (the exceptions are DE, LA, and NY). Such "pharmacy shopping" is less common: approximately half of a percent of opioid users visit five or more pharmacies in a half-year. Figures 5 and 6 present the

\footnotetext{
${ }^{4}$ Because we follow a person longitudinally across years, we can properly account for prescriptions filled in, say, late December and early January.

${ }^{5}$ Pharmacy and prescriber identifiers are not included on our 2007 Part D claims file; therefore, variables using those data are reported for the $2008-2013$ period.
} 
distribution of these variables, again showing the distribution above the threshold in the right panel.

The data collected by a state PDMP is generally limited to prescriptions that have been written and filled in that state. Similarly, access to the data is generally limited to physicians, pharmacists and law enforcement officials in that state. Therefore, to the extent that a PDMP does curtail doctor-shopping it may push some drug abusers to obtain or fill prescriptions in other states. An out-of-state prescriber or pharmacist would be unaware of a suspicious record in another state's PDMP; in addition, the individual's home state PDMP will remain unaware of prescriptions filled in another state. Indeed state and Federal policymakers have complained for more than a decade that uncoordinated state efforts are vulnerable to this behavior (GAO, 2002). Since the Medicare claims data provides information on geographic location, we can test for this type of avoidance behavior. One challenge, however, is that it is not uncommon for Medicare beneficiaries to fill prescriptions out-of-state, either because they live near a state border, are traveling, or live part of the year in another state (e.g., "snow-birds"). To distinguish border-crossing for the purpose of obtaining opioids from other reasons that a patient would fill prescriptions in more than one state, we calculate an individual-level measure of "excess" opioid claims from out-of-state prescribers as

\section{Excess Opioid Claims from OOS Prescriber $=$ \\ $\frac{\sum \text { Opioid Prescriptions from OOS Prescribers }}{\sum \text { O }}-\frac{\sum \text { Non-opioid Prescriptions from OOS Prescribers }}{\sum \text { Non-opioid Presiptios }}$ $\sum$ Opioid Prescriptions $\sum$ Non-opioid Prescriptions}

We construct an analogous measure of excess claims from out-of-state pharmacies; on average, individuals are less likely to fill opioids at an out-of-state pharmacy than to fill non-opioids at such pharmacies, making the mean of this measure in Table 3 negative. As with our other proxies, this type of behavior is rare; only a few percent of opioid takers are more likely to obtain opioids from out-of-state than from in-state providers. Lacking guidance from the literature to suggest a cutoff for these variables, we analyze them as continuous outcomes. In analysis, we standardize this variable to have a mean of zero and a standard deviation of one, meaning its coefficient is directly interpretable as the impact of the policy being tested in terms of standard deviations.

Our last two measures leverage each opioid taker's medical history, as reported in the medical claims files ${ }^{6}$ We use the medical claims to construct an alternative measure of doctor shopping. In the outpatient and physician (carrier) medical claims, we identify all claims where the provider billed for a "new patient" code.7 About a third of opioid takers have at least one new patient visit in a six month period, and the 99th percentile has four or more such visits. Of course, the majority of new patient visits for opioid takers will be innocuous. Again, lacking guidance from the literature, we choose a cutoff of four or more new patient

\footnotetext{
${ }^{6}$ We do not have medical claims for 2013; therefore, these measures are reported for the 2007-2012 period.

${ }^{7}$ A "new patient" visit has a HCPCS code of 99201, 99202, 99203, 99204, or 99205.
} 
visits, a rate of new patient visits that is limited to the top $1.3 \%$ of opioid takers 8 This variable differs from the doctor shopping variable constructed using Part D claims in that this measure includes "unsuccessful" shopping-i.e., visits where a drug-seeking patient was not able to obtain a prescription. We note that policies designed to make opioids harder to obtain could move this measure in either direction - if shopping efforts become less likely to yield opioids, shopping intensity could either increase or decrease.

Finally, the incidence of opioid poisonings is a key outcome of interest. An opioid poisoning incident is indicated by an ICD code for an "opioid related overdose"; we apply the exact codes reported by Meara et al. (2016).9 We should note that while many researchers report on opioid overdose deaths, our measure includes both fatal and non-fatal poisonings. Since the same opioid poisoning incident might generate claims in several settings of care, we simply note whether an individual has any opioid poisoning incidents; the rate in each half-year is $0.2 \%$ of opioid takers.

In addition to allowing us to analyze extreme types of utilization, an important advantage of our microdata compared to the aggregate data used in most other studies is that we can observe the joint distribution of opioid utilization and health outcomes at the individual level. Figure[7illustrates the special role of doctor shopping in opioid abuse and misuse in our dataset. Figure 7 separates our sample population by whether they ever had an opioid poisoning incident. The number within the bar represents the highest number of prescribers ever seen in a half-year, and the height of the bar segment is the percent of beneficiaries who see that number at least once. Overall, the figure shows that most of those who ever experience an opioid poisoning incident are using multiple prescribers. Half of those who experience an opioid poisoning incident met our criterion for doctor shopping at least once, whereas only $18 \%$ of those who are never poisoned do so. Among those who experience an opioid poisoning incident, less than $5 \%$ of individuals never see more than a single prescriber; the comparable figure for those who never experience an opioid poisoning incident is $44 \%$.

Patients that we identify as doctor shoppers are also more likely to obtain extremely large amounts of prescription opioids. This can be seen in Table 4 which reports the correlation of our misuse measures with each other and opioid poisonings. At the same time, the data suggest that doctor shopping is not the only pathway to potential misuse: $33 \%$ of patients who obtain more than seven months' supply see only one

\footnotetext{
${ }^{8}$ In Section 4 , we test robustness to the thresholds used to define misuse for days, prescribers, and pharmacies.

${ }^{9}$ Specifically, an opioid poisoning incident involves ICD code 9650*, E8501, E8502, E9500, or E9800, in any position in the ICD codes of the inpatient, outpatient, and carrier claims. We include poisonings with suicidal intent. We exclude heroin poisoning 96501 from this definition, although several authors have noted the substitutability of heroin and opioids Alpert et al. 2016 Dart et al. 2015, Unick et al. 2013). We do not find enough heroin poisoning incidents in the data to evaluate it as a separate outcome.

Under a policy in effect between 2014 and early 2017, Center for Medicare and Medicaid Services redacted claims for substance use disorders. This policy does not target opioid poisoning incidents per se, but if a single claim reports ICD codes for an opioid poisoning incident and a substance use disorder, the entire claim might be redacted. Our 2012 medical claims are partially affected by redaction; however, we find a similar rate of opioid poisonings in 2012 relative to earlier years, and similar to rates published by Meara et al. (2016), whose claims are not redacted.
} 
prescriber. This suggests the utility of analyzing a number of proxy measures which capture various aspects of opioid misuse. The bottom row of Table 4 indicate that our prescription-based measures of misuse are positively correlated with opioid poisoning, as measured in the medical claims. The relationship can also be seen by running probit regressions of our poisoning outcome on the misuse proxies. Estimated marginal effects from such regressions are reported in Appendix Table A.2. Consistent with the work of Jena et al. (2014), nearly all of our misuse measures bilaterally predict opioid poisoning, with some measures raising the rate of opioid poisoning incidents tenfold.

\subsection{Estimation Strategy}

Our principal analysis tests the impact of a state policy on state-halfyear aggregates of opioid use, misuse, and poisoning incidents. Our regression model is

$$
Y_{s t}=\delta_{s}+\delta_{t}+\beta \mathbf{1}\left(\text { policy }_{s t}\right)+\varepsilon_{s t},
$$

where $Y_{s t}$ is an opioid outcome averaged over a state $\times$ halfyear and $\mathbf{1}\left(\right.$ policy $\left._{s t}\right)$ is 1 if the state has a particular type of PDMP in the half-year. One outcome, the percentage of Part D enrollees using any opioids, is calculated using data from all enrollees in a given state and half-year. For all outcomes related to misuse or abuse, we use the number of enrollees with at least one opioid prescription as the denominator. Each observation is weighted by the number of enrollees represented in the denominator ${ }^{10}$ Each regression contains fixed effects for states $\left(\delta_{s}\right)$ and years $\left(\delta_{t}\right)$ and clusters the standard errors at the state; for our main estimates we also report wild cluster-bootstrap percentile-t confidence intervals Bertrand et al. 2004, Cameron et al. 2008). Brewer et al. (2013) show that this bootstrap provides correct inference - hypothesis testing of correct size - in the presence of autocorrelated errors when the number of treated groups is as low as five.

We use this basic setup to evaluate the impact of two types of PDMPs: those that do and do not require providers to access the data collected by the program. Seventeen states implemented a PDMP without a "must access" provision between 2007 and 2013; ten others implemented a "must access" PDMP 11 Our main hypothesis is that PDMPs will have a stronger impact when providers are required to access the data. To test this, we first estimate the effect of PDMPs that do not have a "must access" provision, dropping the ten "must access" states. Then using the full sample of states we estimate two models to evaluate the effect of the "must access" laws. The first model includes the indicator for non- "must access" laws as an

\footnotetext{
${ }^{10}$ In results available upon request, we find broadly similar estimates when equally weighting states. However, the unweighted standard errors are much larger, suggesting weighting correctly adjusts for heteroskedasticity driven by differences in state sample size (Solon et al. 2015).

11 As described in Section 3.1. we lack shopping outcomes for 2007 and medical services outcomes for 2013. Because of this data limitation, only eight of the ten treatment states identify the policy impact for some outcomes. Details are provided in Appendix Table A.1
} 
independent variable. In the second specification, we combine the states with the PDMPs without a "must access" provision with states having no PDMP at all.

Within the limits imposted by our short-T panel, we can also evaluate "must access" PDMPs within an event study framework. The event study reorients each state's first post-treatment period to zero, and measures the difference between a treatment and control state in the periods prior to and following this period. This analysis serves two purposes. Firstly, systematic differences between treatment and control states in the pre-treatment period could suggest nonparallel trends or policy endogeneity. Secondly, evaluating the impact of the treatment several periods post implementation can suggest whether the policy's impact fades out or grows over time. The event study estimates the following equation:

$$
Y_{s t}=\delta_{s}+\delta_{t}+\sum_{h=-4,-3, \ldots 0 \ldots 2} \beta_{h} T_{s h}+\varepsilon_{s t}
$$

where $T_{s h}=1$ if state $s$ implemented a must access PDMP $h$ half-years ago (or if $h$ is negative, will implement a PDMP $-h$ half-years in the future.) The first post period is denoted by $h=0$, and we combine all post periods after the third $(h=2)$ into the third.

\subsection{Methodological Limitations}

The use of Medicare claims data for this analysis brings several advantages: individual-level data allows us to measure extremes of the distribution, the large sample size provides many observations of rare outcomes, and the medical claims allow us to directly observe the linkage between opioid utilization and poisonings. However, the Part D program only began in 2006, several years into the escalation of opioid utilization. We therefore have only a short time period on which to assess state-specific trends in opioid misuse prior to PDMP implementation.

Other limitations of our dataset are inherent to administrative claims. Part D claims could undercount an individual's utilization if they purchase opioids on the street. In addition, a Medicare beneficiary can fill opioid prescriptions using cash instead of Part D benefits, although over our sample period there was little reason to do so. The possibility of beneficiaries obtaining opioids outside of Medicare Part D is not a concern for our analysis of opioid poisonings, although there we rely on the accuracy of medical coding for fee-for-service beneficiaries. Finally, our perspective could be affected by beneficiaries in jail or prison. Medicare does not pay claims during periods of incarceration, but the standard claims files do not reflect incarceration status 12 In principle, a "must access" PDMP could reduce misuse rates via the channel of incarceration.

\footnotetext{
${ }^{12}$ Individuals remain enrolled in Part A and can remain in Parts B or D if they or a public entity continue to pay premiums.
} 
Finally, our 5\% random sample is well-designed for characterizing the experience of Medicare enrollees. However, it is not possible to use these data for prescriber-level analyses. A slight majority of opioid prescribers write only a single prescription to one of our sampled individuals, and even at the $99^{\text {th }}$ percentile the prescriber writes prescriptions to only six individuals. We leave a fuller investigation of how prescribers respond to opioid control policies to future work.

\section{Results}

\subsection{Effect of a PDMP Without a "Must Access" Provision on Opioid Misuse and Poisonings}

In Table 5 , we report the results of our difference-in-difference strategy for the PDMPs that do not require providers to access the database, dropping the ten states that implement a "must access"' PDMP from the analysis. Most of our point estimates cannot be distinguished from zero. The exceptions are an increase in the rate of filling opioids at five or more pharmacies, and an increase in the share of opioid takers with at least four new patient visits. The first result is clearly contrary to the sign we expect from a successful opioid control policy. The hypothesized effect for the number of new patient visits is theoretically ambiguous, though it seems more plausible that a successful PDMP would reduce such visits. Indeed, that is what we find for "must access" PDMPs. This logic, combined with the fact that none of the estimates for the quantity measures are statistically significant, suggests that positive and significant coefficient on the $4+$ new patients variable should be discounted.

In order for a PDMP to provide useful information to a prescriber or pharmacist who checks it, the PDMP needs to first populate its database of utilization 13 The implementation of a PDMP at time $t$ is actually the implementation of data reporting requirements, and so it may take time for a provider to see a representative record for any patient. Therefore, in the third panel of this table, we again test for the impact of a non-must access PDMP lagging the implementation date by six months. That is to say, we assume a newly-implemented PDMP is only effective six months after its actual implementation date. We again find that a PDMP without a "must access" provision is largely ineffective. Overall, the results in Table 5 are consistent with our hypothesis that PDMP that rely entirely on the voluntary participation of providers are unlikely to be successful.

\footnotetext{
${ }^{13}$ Among our ten states implementing a "must access" PDMP, only Delaware did not first have a non- "must access" PDMP which had already begun collecting data.
} 


\subsection{The Effect of "Must Access" PDMPs on Opioid Misuse and Poisonings}

In Table 6, we report the results of estimating Equation 1 for a "must access" PDMP. The models reported in the upper panel also include indicators for the presence of a non- "must access" PDMP. Because we find few significant differences between the seventeen states with non- "must access" laws and other states that did not implement a new PDMP during this period, our preferred model combines these two categories of states into a single control group. Results from this more parsimonious specification are reported in the lower panel of Table 6. The two models produce similar point estimates for the effect of a "must access" PDMP. For every estimate, we report below it the 95 percent wild cluster-bootstrap percentile-t confidence interval, with CIs that exclude zero in bold. Our inference is unaffected by this procedure 14

Our first set of outcomes reflect the quantity of opioids obtained. A "must access" PDMP is associated with a statistically significant $2.4 \%$ decline in the share of Part D enrollees taking opioids. Similarly, we find a $6 \%$ decline in the share of opioid takers with overlapping claims, and a $5 \%$ decline (significant at the ten percent level) in the share with more than seven months supply. In contrast to these statistically significant effects, we estimate a fairly precise zero on the share of those obtaining more than $120 \mathrm{MED} /$ day.

We find larger declines in our shopping outcomes - a statistically significant $8 \%$ fall in the share of individuals obtaining opioids from five or more prescribers and a $16 \%$ decline for five or more pharmacies. The passage of a "must access" PDMP may prompt individuals to cross state lines in search of less-regulated prescribers and pharmacies. We find evidence consistent with that hypothesis for the case of out-of-state prescribers: a "must access" PDMP raises the rate at which individuals obtain prescriptions from out-ofstate prescribers by about a third of a standard deviation, although this result is only significant at the ten percent level. The next column tests whether a "must access" PDMP affects opioid takers' number of new patient visits (measured from the medical claims). We find a $14 \%$ decline in this rate (significant at the five percent level).

Each new patient visit is reimbursed by Medicare under standard rules, even if the visit is motivated purely by opioid-seeking behavior and no other care takes place 15 If the decline in new patient visits is not offset by other episodes of care, then the reduction in new patient visits is net Federal savings. To calculate these savings, we estimate the impact of a "must access" PDMP on the average number of new patient visits, which yields a coefficient of -0.024 (SE 0.010). When multiplied by the cost of a "new patient" visit, on average $\$ 119$ in our 2012 medical claims, and the represented population, we find that a "must access"

\footnotetext{
${ }^{14}$ We also computed the pairs cluster-bootstrap percentile-t CIs. The pairs cluster assigns a given state's outcomes to an alternative state's policy history, obtaining the distribution of estimates under a null hypothesis of no effect. We find similar CIs using this procedure; results available upon request.

${ }^{15}$ We do not explicitly test how a "must access" PDMP affects the volume of medical services. However, in results available upon request, we find that a "must access" PDMP reduces the share of individuals seeing a high number of providers, although for some thresholds the effect is insignificant.
} 
PDMP in every state would reduces outlays on new patient visits by $\$ 174$ million each half-year.

The final column tests whether a "must access" PDMP affects an important health outcome: opioid poisonings. Despite the fact that we find negative effects on several measures of misuse which are positively correlated with opioid poisonings, we cannot reject the null hypothesis that these programs reduce poisonings. The estimated coefficients in the last column of the table are negative, but they are small relative to their standard errors.

An extension of this analysis shows that our results are not sensitive to the thresholds used to define misuse. In Figure 8, we test the impact of a "must access" PDMP using Equation 1 on various thresholds for days supply, number of prescribers, number of pharmacies, and number of new patient visits. The yaxis reports the percentage change associated with a "must access" PDMP, and the mean of the variable is reported along the x-axis. Point estimates for each threshold are always negative; however, it is clear that standard errors grow as the threshold cuts off a smaller share of opioid takers.

\subsection{Model Assumptions: Pretrends, Co-Occurring Policy Changes, and Policy Heterogeneity}

An assumption underlying our difference-in-difference strategy is that states that implement a "must access" PDMP were similar prior to implementation to those that do not. The event history model presented in Equation 2 represents a standard way to evaluate this assumption; an additional benefit of this specification is that it can inform us how a policy's impact increases or decreases with time since implementation. The results of estimating Equation 2 are reported in Figure 9. We depict each $\beta_{h}$ for four half-years prior to implementation and three half-years post implementation. $\beta_{h}$ signifies the difference between implementing and nonimplementing states on this measure $h$ periods before or after implementation, net of state and calendar half-year dummies. We drop states that implement in either the first or last year of our panel, which leaves us six states that contribute to identification of every $\beta_{h}$, eliminating impacts on $\beta_{h}$ that result from composition alone. In general, the coefficients are not significantly different from zero, suggesting that prior to implementation the states that implemented "must access" PDMPs did not differ from controls. However, some of the results are suggestive of anticipatory effects, particularly for the pharmacy shopping outcome. We note that, in the lead-up to the implementation of a "must access" PDMP, all states except Delaware had existing PDMPs which allowed, but did not require, provider access. Since the policy process for a change like a "must access" PDMP would have involved consultation with health care providers, it is possible that they were made aware in the late pre-period of the scope of the problem and the potential applicability of the PDMP to which they already had access. Presumably, in advance of the official start date, the agency managing the PDMP would have begun encouraging providers to create PDMP accounts and begin accessing 
the data. Similarly, providers may have made changes in workflow earlier than required in order to ensure they were in compliance with the law on its first applicable date. If so, then the implementation timing of a "must access" PDMP is actually fuzzy, with the true post-period beginning earlier than what we record. With respect to the impact of the policy over time in the post policy, there is no systematic pattern of either growth or reduction in impacts over time.

Another important assumption that underlies our interpretation of the results is that they are not picking up the effect of other opioid-related policies that states were implementing around the same time. In some cases, the legislation that established "must access" rules contained other measures aimed at strengthening the PDMP. The Prescription Drug Abuse Policy System describes a broad set of PDMP characteristics ${ }^{16}$ For each of ten states implementing a "must access" PDMP, we looked for any policies implemented at the same time in more than one "must access" state. Three states - Kentucky, West Virginia, and New York began to allow providers' "delegates" to access the PDMP at the same time as the "must access" provision began. Allowing delegates lowers the labor costs of accessing the PDMP by enabling, for example, a medical assistant to query the PDMP instead of the prescribing physician. Three states - Ohio, Kentucky, and New York - increased the frequency with which PDMP data must be updated. Increasing frequency of reporting, e.g. from weekly to daily, improves the quality of data available to a provider accessing the PDMP. States enacted policies besides PDMPs as well. The dataset collected and analyzed by Meara et al. (2016) identifies laws that set limits on days supply, establish new requirement for the physician-patient relationship and verifying patient identification at pharmacies, increase the use of tamper-resistant prescription pads, and establish new regulations pertaining to pain clinics. There were two instances where states enacted one of these policies close to the time they implemented a "must access" rule: pain clinic laws in Kentucky and Ohio.

Intuitively, the two PDMP-related provisions can be seen as complements laws requiring PDMP access. Providers who access a PDMP will obtain more useful information when the database is updated more frequently and the cost of complying with a "must access" requirement will be lower when providers can delegate the task of checking the database. Therefore, we first test whether these policies have an independent effect when passed in the absence of a "must access" law. If they have little or no impact on misuse outcomes when passed alone, they cannot be responsible for the policy impacts reported in Table6. We view pain clinic laws as targeting a slightly different channel of misuse than PDMP-related policies. "Must access" policies bring information to the mass of providers, including many who prescribe opioids only rarely, while pain

\footnotetext{
${ }^{16}$ This dataset is a comprehensive resource on all aspects of PDMPs: which agency operates the PDMP; who - prescribers, pharmacists, patients, law enforcement, out-of-state entities - may access the PDMP and under what circumstances; whether the PDMP is permitted or required (or neither) to identify suspicious activity and whether it is permitted or required (or neither) to inform licensing boards, law enforcement, providers, or patients of such activity; and which substances must be reported to the PDMP and at what frequency.
} 
clinic laws directly regulate the behavior of a small share of providers who account for a disproportionate share of all opioid prescribing. The two approaches may both be effective against different patterns of opioid abuse.

We test for an independent effect of each of the three co-occurring policies using data on the 41 states without "must access" laws. Ten states among the 41 began to allow delegates to access their PDMPs, 20 increased the frequency of PDMP reporting, and 3 implemented pain clinic regulations (Table 1). The results from this analysis are presented in Table 7 . To facilitate comparisons, the first row reports the results from Table 6. Neither allowing delegates nor increasing reporting frequency have estimated effects that are significant at the .05 level, so we conclude that these policies do not affect opioid misuse when providers are also not required to access the PDMP. We find that pain clinic regulations are associated with an increase in the rate of four or more new patient visits and the use of out-of-state pharmacies. These coefficients have the opposite sign as our "must access" estimates, which suggests that failing to account for pain clinic laws may cause the magnitude of the latter to be understated. The other significant coefficient, on use of five or more pharmacies, has the same sign and similar magnitude as our main estimate. Taken as a whole, these results do not suggest that our "must access" results are being driven by other co-occurring policies.

An alternative way to test the sensitivity of our results is to simply add controls for those laws to our main regressions. The policy variation to precisely parse the effects of these different provisions is somewhat limited, since as stated some are passed by the same states at the same time. In Appendix Table A.3 we present estimates from such regressions. In general, controlling for these other policies moves the effects of a "must access" PDMP slightly towards zero, although the point estimates never differ significantly from our preferred, more parsimonious specification. We see that when controlling for pain clinic laws "must access" PDMPs are still associated with a reduction in the use of five or more pharmacies, which supports our hypothesis that these laws affect different channels of misuse.

The results presented so far do not account for differences among "must access" laws related to the types of providers targeted and the discretion providers are granted (see Section 2). To consider the importance of these differences, we categorize our ten states' laws into three subtypes: limited laws that apply only to certain ingredients (Methadone in OK) or settings of care (pain clinics in LA), discretionary laws that require the provider to access the PDMP if they are suspicious (NV, DE, and $\mathrm{OH}$ ), and broad laws that apply to all ingredients and settings and do not rely on provider suspicion (KY, WV, NM, TN, and NY). Figure 10 shows the point estimates we obtain if we include each subtype of policy as independent variables in a single regression. The gray bar shows our overall estimate, for reference. Among our quantity outcomes (top four figures), the pattern of estimates suggests that broad policies have stronger effects than discretionary laws, which in turn appear to be stronger than limited policies (although the differences between the subtypes 
are not always significant). The other outcomes do not display such a clear pattern. However, even limited laws significantly affect shopping outcomes, and in most cases the estimate for each subtype cannot be distinguished from the overall estimate.

As an addendum to this analysis, we test the robustness of our estimates to dropping one of our implementing states. These results are presented in Appendix Figure A.1 A gray bar again represents the overall estimate, and each estimate drops the state noted on the x-axis (which orders states by implementation date). Finding that removing a single state significantly changes our estimated policy impact would suggest that special circumstances in that state are actually driving our results. Instead we find that point estimates are very similar when estimated on a subset of nine or seven implementing states.

\subsection{Results by Subsample}

In addition to our main analysis, which is based on state-year averages for all opioid users, we also analyze the same outcomes calculated for key subsamples of Medicare enrollees. As noted, it is generally believed that the problem of opioid abuse is most serious among lower-income Medicare beneficiaries and those who qualify due to disability. Therefore we conduct separate analyses by Medicare eligibility category. Table 8 tests the impact of a "must access" PDMP on aggregate outcomes within four Medicare subsamples. We find that the probability of taking opioids is reduced among all groups (insignificantly for disabled and nondually eligible.) However, the effects of "must access" PDMPs on measures of high quantity or shopping are primarily found among the low-income disabled. In fact, given the number of dual disabled and the point estimates of their behavioral response, the impact on the low-income disabled is responsible for more than two-thirds of the overall Medicare impact on 211+ days supply, overlapping claims, five or more prescribers or pharmacies, and excess out-of-state pharmacies ${ }^{17}$ Consistent with the literature reviewed in Section 2 . the disabled are more likely to have utilization patterns that suggest "misuse" and have a much higher rate of opioid poisoning incidents. It's possible that a "must access" PDMP has larger effects in the low-income disabled because the policy is well-targeted towards the type of "misuse" that is more common among this subpopulation. Alternatively, a "must access" PDMP may simply have a larger impact among the low-income disabled population. If physicians are more likely to suspect "misuse" among the low-income disabled, then a "must access" provision in states with a discretionary policy may result in more PDMP checks for this group than for elderly opioid users.

Table 9 considers the subsample of 41,709 individuals who met our doctor shopping criteria - obtained opioids from five or more prescribers in a six month period - at least once in their state's pre period (any

\footnotetext{
${ }^{17}$ To make these calculations, we multiple the subsample's effect by its size, and then divide by product of the overall sample and its size. For the case of $211+$ days supply, the calculation is $\left(-0.0128^{*} 940,362\right.$ dual disabled)/(-.00429*3,703,389 opioid takers).
} 
time for control states). On average, a state-halfyear still contains more than 600 individuals. If a "must access" PDMP is successful, it should result in behavior change among these individuals. Consistent with this, effects among this sample of previous doctor shoppers are larger in magnitude than among Medicare beneficiaries as a whole; for example, the share of beneficiaries with overlapping claims and the use of five or more pharmacies falls by a quarter, and four or more new patient visits falls by $37 \%$. However, we still do not find any reduction in opioid poisoning incidents among this group; the insignificant point estimate amounts to only a $10 \%$ reduction.

Appendix Table A.4 describes the impact of a "must access" PDMP on subsamples defined by health status. An unintended consequence of a "must access" PDMP might be a "chilling effect" on appropriate opioid utilization. The top two panels of the table report the effect of a "must access" PDMP on statehalfyear aggregates of cancer patients and those without cancer. We limit this analysis to 2007-2012 because we do not have the medical claims to identify cancer for 2013. A first note is that while taking opioids is more common among cancer patients, our measures of opioid "misuse" are not markedly higher, suggesting we are not mislabeling high but appropriate utilization too often. Among the quantity outcomes, a "must access" PDMP actually raises the rate at which cancer patients obtain high quantities of opioids, perhaps because providers are more comfortable allowing high quantities when they are certain of the absence of misuse. Our results show that a "must access" PDMP affects shopping outcomes among both cancer patients and those without cancer. Finally, we find that a "must access" PDMP reduces poisonings among cancer patients. In results available upon request, we find that this effect is unchanged when we exclude the small number of poisonings explicitly characterized as "with suicidal intent". The table shows that a "must access" PDMP reduces measures of misuse among those without cancer, without impeding the utilization of cancer patients. Inasmuch as some cancer patients show behavior consistent with shopping, such behavior becomes less common after a "must access" PDMP is implemented. The second two panels consider two different subsamples: those who die in the half-year versus those who do not. Again, while those who die are more likely to take opioids, they are if anything less likely to meet our "misuse" criteria 18 In this comparison, it's clear that the effects of a "must access" PDMP are driven by those who do not die in the half-year. The utilization of those who die is less affected, although there is a reduction in overlapping claims and the use of five or more pharmacies.

\subsection{Placebo Test: "Must Access" PDMPs' Effect on Non-opioids}

Finally, we also estimate a set of "placebo" regressions that test for an effect of PDMP laws on the use or "abuse" of statins and antidepressants. If a "must access" PDMP is correlated for some reason with general

\footnotetext{
${ }^{18}$ We make no adjustment for the amount of time in the half-year the patient was alive. If utilization were identical, means of measures would still be lower among those who die in the half-year due to censoring.
} 
trends in prescription drug utilization or prescribing patterns, we will incorrectly attribute the change in opioid misuse measures to the "must access" PDMP. As a placebo test, Table 10 looks at the impact of a "must access" PDMP on outcomes for statins and antidepressants, which are taken by a similar share of the Medicare population. The excess out-of-state prescriber and pharmacy measures are not standardized in this table to show their levels across these three types of drugs. As mentioned above, it is vanishingly rare to obtain statins or antidepressants from five or more prescribers or pharmacies. However, these other types of drugs are more often provided in large quantities or in ways that create overlap in fill dates. One interpretation is that individuals commonly experiment with drugs in these categories, and that prescribers are comfortable allowing overlapping claims and large quantities among drugs with low potential for overdose and abuse. We find no significant effects of a "must access" PDMP on outcomes for drug types besides opioids.

\section{Conclusion}

Several key conclusions emerge from our analysis. First, our results suggest that PDMPs that do not require provider participation are not effective in reducing questionable or inappropriate use of prescription opioids. In contrast, we do find evidence that "must access" PDMPs have the desired effect of curbing certain types of extreme utilization. Specifically, such policies reduce several measures of excessive quantity and shopping behavior. The strongest laws, which cover all ingredients and settings of care and do not require providers to be suspicious, have larger effects on utilization than weaker laws, but even "limited" and "discretionary" laws lower rates of shopping behavior. Several additional analyses suggest that these estimates represent causal effects. We show that states that pass a "must access" PDMP are not dissimilar to states that do not on our key measures during the pre period. Since our sample period was a time of active policy experimentation among states, we search for policies that co-occur with "must access" laws, but no potential confounding policies have strong independent effects when passed in the absence of a "must access" PDMP. Finally, our results are very robust to dropping any of our implementing states. Subsample analyses show that, as we expect, the policy's impacts are concentrated among previous misusers and low-income disabled enrollees, who have the highest rates of misuse measures.

Although these results point to the effectiveness of "must access" PDMPs, other results suggest the limits of this policy. We find no statistically significant effect on a key medical outcome: opioid poisoning incidents. This is despite the fact that several outcomes for which we find significant effects are themselves positively correlated with poisoning. The explanation for this result may have to do with the fact that in the Medicare Part D data that we analyze, we observe prescription fills rather than actual utilization. Perhaps poisonings do not fall because Medicare beneficiaries who are misusing opioids are able to find other ways to maintain consumption. The fact that we find some evidence that stronger PDMP laws induce some 
beneficiaries to turn to out-of-state sources is suggestive of this type of compensatory effect. There are other possible spillover effects, such as substitution to street sources of prescription opioids or heroin that we are not able to measure. Alternatively, the PDMP effects that we observe may be driven by a reduction in opioid diversion. That is, rather than reducing the amount of opioids that beneficiaries take, these laws may reduce the amount that they sell to others.

Another possibility is that a "must access" PDMP reduces the rate at which individuals become opioid misusers, delaying the effects on poisonings beyond our sample period. Borgschulte et al. (2016) suggest that the impact of opioid control policies interacts with a state's capacity to provide substance abuse treatment to those who are now incentivized to reduce utilization.

To our knowledge, no evaluation yet exists of recent changes CMS has made to opioid access policies in Part D A collaboration between CMS and state PDMPs could allow states access to CMS's data resources, allowing improved identification of suspicious patterns of prescribing and utilization and smoother sharing of information across state lines. 


\section{References}

Agrawal, Shantanu, "Combatting The Opioid Epidemic: A Review of Anti-Abuse Efforts By Federal Authorities and Private Insurers, Testimony before U.S. Senate Committee on Homeland Security and Government Affairs," Technical Report, CMS, Washington, DC September 2016. Available at https://www. hhs.gov/about/agencies/asl/testimony/2016-09/a-review-of-anti-abuse-efforts/index.html.

Alpert, Abby, David Powell, and Rosalie Liccardo Pacula, "Supply-Side Drug Policy in the Presence of Substitutes: Evidence from the Introduction of Abuse-Deterrent Opioids," December 2016. Available at http://www.rand.org/pubs/working_papers/WR1181.html.

Arditi, Lynn, "New law: Health-care providers must register in prescription database," Providence Journal, 2014, May 29, 2014.

Bertrand, Marianne, Esther Duflo, and Sendhil Mullainathan, "How Much Should We Trust Differences-In-Differences Estimates," The Quarterly Journal of Economics, 2004, 119 (1).

Blum, Jonathan, "Curbing Prescription Drug Abuse in Medicare, Testimony before U.S. Senate Committee on Homeland Security and Government Affairs," Technical Report, Director, Center for Medicare Management, Washington, DC June 2013. Available at http://www.hhs.gov/asl/testify/2013/06/4483.html

Borgschulte, Mark, Adriana Corredor-Waldron, and Guillermo Marshall, "A Path Out: Prescription Drug Abuse and Suicide," December 2016. Available at https://sites.google.com/site/ markborgschulte/research.

Brady, Joanne E., Hannah Wunsch, Charles J. DiMaggio, Barbara H. Lang, James Giglio, and Guohua Li, "Prescription drug monitoring and dispensing of prescription opioids," Public Health Reports, 2014, 129.

Brewer, Mike, Thomas F. Crossley, and Robert Joyce, "Inference with Difference-in-Differences Revisited," November 2013. IZA Discussion Paper No. 7742.

Cameron, A. Colin, Jonah B. Gelbach, and Douglas L. Miller, "Bootstrap-Based Improvements for Inference with Clustered Errors," The Review of Economics and Statistics, 2008, 90 (3).

Case, Anne and Angus Deaton, "Rising morbidity and mortality in midlife among white non-Hispanic Americans in the 21st century," Proceedings of the National Academy of Sciences, 2015, 112 (49), 1507815083. 
Chen, Li Hui, Holly Hedegaard, and Margaret Warner, "Drug-poisoning Deaths Involving Opioid Analgesics: United States, 1999-2011," Technical Report, National Center for Health Statistics, Washington, DC September 2014. NCHS Data Brief No. 166.

CMS, "Opioid Morphine Equivalent Conversion Factors," https://www.cms.gov/ Medicare/Prescription-Drug-Coverage/PrescriptionDrugCovContra/Downloads/ Opioid-Morphine-EQ-Conversion-Factors-March-2015.pdf 2015. Accessed: February 2, 2016.

Dart, Richard C., Hilary L. Surratt, Theodore J. Cicero, Mark W. Parrino, Geoff Severtson, Becki Bucher-Bartelson, and Jody L. Green, "Trends in Opioid Analgesic Abuse and Mortality in the United States," New England Journal of Medicine, 2015, 372 (3).

Davis, Corey S., Matthew Pierce, and Nabarun Dasgupta, "Evolution and Convergence of State Laws Governing Controlled Substance Prescription Monitoring Programs, 1998-2011," American Journal of Public Health, August 2014, 104.

Dowell, Deborah, Kun Zhang, Rita K. Noonan, and Jason M. Hockenberry, "Mandatory Provider Review And Pain Clinic Laws Reduce The Amounts Of Opioids Prescribed And Overdose Death Rates," Health Affairs, 2016, 35 (10), 1876-1883.

GAO, "State Monitoring Programs Provide Useful Tool to Reduce Diversion," Technical Report, Government Accountability Office, Washington, DC May 2002. GAO-02-634.

_ , "Instances of Questionable Access to Prescription Drugs," Technical Report, Government Accountability Office, Washington, DC September 2011. GAO-11-699.

Gourlay, Kristin, "Fighting Prescription Drug Abuse, One Log In At a Time," Rhode Island Public Radio, 2013.

Haegerich, Tamara M., Leonard J. Paulozzi, Brian J. Manns, and Christopher M. Jones, "What we know, and don't know, about the impact of state policy and systems-level interventions on prescription drug overdose," Drug and Alcohol Dependence, 2014, 145, 34-47.

Haffajee, Rebecca L., Anupam B. Jena, and Scott G. Weiner, "Mandatory Use of Prescription Drug Monitoring Programs," JAMA, 2015, 313 (9), 891-892.

Islam, M. Mofizul and Ian S McRae, "An Inevitable Wave of Prescription Drug Monitoring Programs in the Context of Prescription Opioids: Pros, Cons and Tensions," BMC Pharmacology $E$ Toxicology, 2014, 15 (46). 
Jena, Anupam B., Dana Goldman, Lesley Weaver, and Pinar Karaca-Mandic, "Opioid Prescribing By Multiple Providers in Medicare: Retrospective Observational Study of Insurance Claims," British Medical Journal, 2014, 348 .

Kunins, Hillary V., Thomas A. Farley, and Deborah Dowell, "Guidelines for opioid prescription: why emergency physicians need support," Annals of Internal Medicine, 2013, 158.

Levy, Benjamin, Leonard Paulozzi, Karin A. Mack, and Christopher M. Jones, "Trends in Opioid Analgesic Prescribing Rates by Specialty, U.S., 20072012," American Journal of Preventive Medicine, 2015, $49(3), 409-413$.

Li, Guohua, Joanne E. Brady, Barbara H. Lang, James Giglio, Hannah Wunsch, and Charles DiMaggio, "Prescription drug monitoring and drug overdose mortality," Injury Epidemiology, 2014, 1 (1), 1-8.

Manchikanti, Laxmaiah, Bert Fellows, Hary Ailinani, and Vidyasagar Pampati, "Therapeutic use, abuse, and nonmedical use of opioids: a ten-year perspective," Pain Physician, February 2010, 13.

Meara, Ellen, Jill R. Horwitz, Wilson Powell, Lynn McClelland, Weiping Zhou, A. James O'Malley, and Nancy E. Morden, "State Legal Restrictions and Prescription-Opioid Use among Disabled Adults," New England Journal of Medicine, 2016, 375 (1), 44-53.

Morden, Nancy E., Jeffrey C. Munson, Carrie H. Colla, Jonathan Skinner, Julie P.W. Bynum, Weiping Zhou, and Ellen Meara, "Prescription Opioid Use Among Disabled Medicare Beneficiaries: Intesity, Trends, and Regional Variation," Medical Care, September 2014, 52 (9).

NSDUH, "National Survey on Drug Use and Health: Summary of National Findings," September 2014. Available at http://www.samhsa.gov/data/sites/default/files/NSDUHresultsPDFWHTML2013/ Web/NSDUHresults2013.htm some results from authors' tabulation at http://www.icpsr.umich.edu/ icpsrweb/SAMHDA/studies/35509/datasets/1/sdaxml.

Ohio Bureau of Workers' Compensation, "MED Table," https://www.bwc.ohio.gov/downloads/ blankpdf/MEDTable.pdf 2016. Accessed: February 2, 2016.

Palliative.org, "INSTRUCTIONS FOR MORPHINE EQUIVALENT DAILY DOSE (MEDD)," http:// palliative.org/NewPC/_pdfs/tools/INSTRUCTIONsMEDD.pdf 2016. Accessed: February 2, 2016.

Pasero, Christine L. and Margo McCaffery, "Pain Ratings: The Fifth Vital Sign," American Journal of Nursing, February 1997, $9 \%$. 
Patrick, Stephen W., Carrie E. Fry, Timothy F. Jones, and Melinda B. Buntin, "Implementation Of Prescription Drug Monitoring Programs Associated With Reductions In Opioid-Related Death Rates," Health Affairs, 2016, 35 (7), 1324-1332.

Paulozzi, Leonard J., Edwin M. Kilbourne, and Hema A. Desai, "Prescription Drug Monitoring Programs and Death Rates from Drug Overdose," Pain Medicine, May 2011, 12 (5), $747-54$.

PDMP Center of Excellence, "Mandating PDMP participation by medical providers: current status and experience in selected states," Technical Report, Brandeis University, Waltham, MA October 2014. Available at http://www.pdmpexcellence.org/sites/all/pdfs/COE_briefing_mandates_2nd_rev.pdf

Poston, Rebecca, "E-FORCSE 2011-2012 Prescription Drug Monitoring Program Annual Report," December 2012. Available at http://www.floridahealth.gov/statistics-and-data/e-forcse/ news-reports/_documents/2011-2012pdmp-annual-report.pdf

Reifler, Liza M., Danna Droz, J. Elise Bailey, Sidney H. Schnoll, Reginald Fant, Richard C. Dart, and Becki Bucher-Bartelson, "Do Prescription Monitoring Programs Impact State Trends in Opioid Abuse/Misuse?," Pain Medicine, 2012, 13.

Solon, Gary, Steven J. Haider, and Jeffrey Wooldridge, "What Are We Weighting For?," Journal of Human Resources, 2015, 50 (2), 301-316.

Unick, George Jay, Daniel Rosenblum, Sarah Mars, and Daniel Ciccarone, "Intertwined Epidemics: National Demographic Trends in Hospitalizations for Heroin- and Opioid-Related Overdoses, 1993-2009," PLOS One, February 2013, 8 (2).

Volkow, Nora D., "Testimony before the Senate Caucus on International Narcotics Control on America's Addiction to Opioids: Heroin and Prescription Drug Abuse," $2014 . \quad$ Available at www.drugabuse.gov/about-nida/legislative-activities/testimony-to-congress/2015/ americas-addiction-to-opioids-heroin-prescription-drug-abuse

Washington State Agency Medical Directors' Group, "Interagency guideline on opioid dosing for chronic non-cancer pain: an educational aid to improve care and safety with opioid treatment," http: //www.agencymeddirectors.wa.gov/files/opioidgdline.pdf 2010. Accessed: February 5, 2016.

West, Nancy A., Stevan G. Severtson, Jody L. Green, and Richard C. Dart, "Trends in Abuse and Misuse of Prescription Opioids Among Older Adults," Drug and Alcohol Dependence, $2015,149$. 


White House, "Obama Administration Announces Public and Private Sec-
tor Efforts to Address Prescription Drug Abuse and Heroin Use," October
2015. Available at https://www.whitehouse-gov/the-press-office/2015/10/21/
fact-sheet-obama-administration-announces-public-and-private-sector.

Wisconsin Prescription Drug Monitoring Program, "Training Guide for Wisconsin Practitioners and Pharmacists," http://dsps.wi.gov/Documents/PDMP/Practitioners_Pharmacists_Training_Guide. pdf October 2013. Accessed: February 2, 2016. 




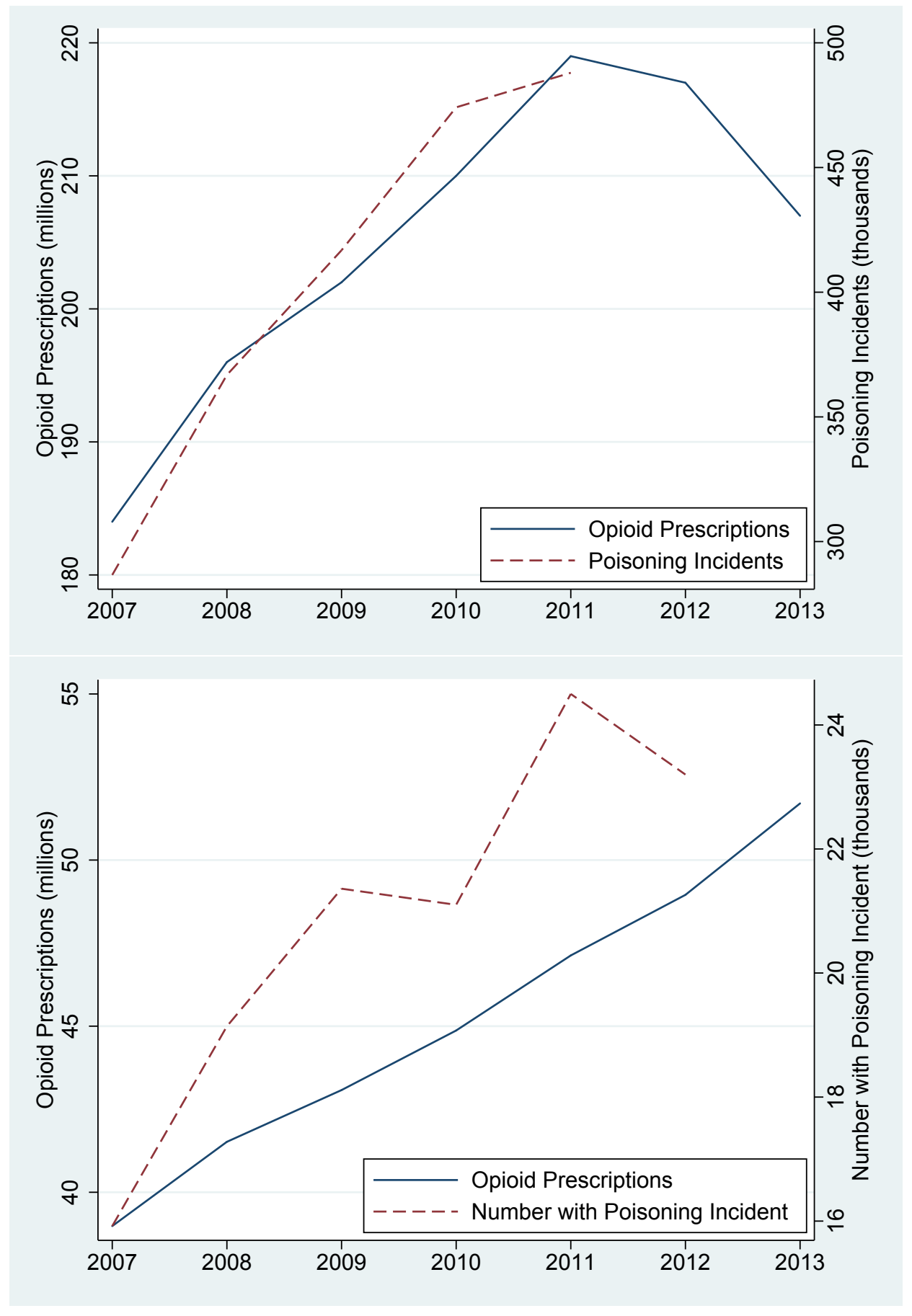

Figure 2: Opioid Utilization and Poisoning, Overall (top) and in Medicare Part D (bottom)

Overall opioid prescriptions collected from Volkow (2014). Overall poisoning incidents, which reflect emergency department visits alone, are collected from the Drug Abuse Warning Network Emergency Department Data for 2007 to 2011 (the dataset was discontinued in 2011). Medicare opioid prescriptions (available 2007-2013) and poisoning incidents (available 2007-2012) are from a $5 \%$ random sample of enrollees in free-standing Part D and fee-for-service Medicare. 
Table 1: State Laws

\begin{tabular}{|c|c|c|c|c|c|}
\hline State & Any PDMP & $\begin{array}{c}\text { "Must Access" } \\
\text { PDMP }\end{array}$ & $\begin{array}{l}\text { PDMP Allows } \\
\text { Delegates }\end{array}$ & $\begin{array}{c}\text { Increase } \\
\text { Reporting } \\
\text { Frequency }\end{array}$ & $\begin{array}{l}\text { Pain Clinic } \\
\text { Regulation }\end{array}$ \\
\hline \multicolumn{6}{|l|}{ Alabama } \\
\hline Alaska & 2008h2 & & & 2012h1 & \\
\hline Arizona & 2007h2 & & & & \\
\hline Arkansas & 2011h2 & & & 2013h1 & \\
\hline \multicolumn{6}{|l|}{ California } \\
\hline Connecticut & & & & 2013h2 & \\
\hline Delaware & 2012h1 & 2012h1 & & & \\
\hline \multicolumn{6}{|l|}{ District of Columbia } \\
\hline Florida & 2009h2 & & & 2011h2 & 2011h1 \\
\hline Georgia & 2011h2 & & & & \\
\hline Indiana & & & 2007h2 & 2007h2 & \\
\hline Iowa & & & & 2009h2 & \\
\hline Kansas & 2008h2 & & & 2011h1 & \\
\hline Kentucky & & $2012 \mathrm{~h} 2$ & 2012h2 & 2012h2 & $2012 \mathrm{~h} 2$ \\
\hline Louisiana & & 2008h1 & 2013h2 & 2013h1 & \\
\hline Maine & & & & 2011h2 & \\
\hline Maryland & 2011h2 & & & 2013h1 & \\
\hline Massachusetts & & & 2011 h2 & 2010h2 & \\
\hline \multicolumn{6}{|l|}{ Michigan } \\
\hline Minnesota & 2007h2 & & 2010h2 & & \\
\hline Mississippi & & & & & $2012 \mathrm{~h} 2$ \\
\hline New York & & 2013h2 & 2013h2 & 2013h2 & \\
\hline North Carolina & & & 2013h2 & 2010h1 & \\
\hline North Dakota & 2007h2 & & & 2011h2 & \\
\hline Ohio & & 2012h1 & 2013h1 & 2012h1 & $2011 \mathrm{~h} 2$ \\
\hline Oklahoma & & 2011h1 & & 2009h2 & \\
\hline Oregon & 2009h2 & & 2011h2 & 2010h2 & \\
\hline \multicolumn{6}{|l|}{ Pennsylvania } \\
\hline \multicolumn{6}{|l|}{ Rhode Island } \\
\hline \multicolumn{6}{|l|}{ South Carolina } \\
\hline South Dakota & 2010h2 & & & & \\
\hline Tennessee & & 2013h2 & $2012 \mathrm{~h} 2$ & $2012 \mathrm{~h} 2$ & $2012 \mathrm{~h} 2$ \\
\hline Texas & & & & 2011h2 & 2010h1 \\
\hline Utah & & & 2009h2 & & \\
\hline Vermont & & & $2013 h 2$ & 2008h2 & \\
\hline Virginia & & & 2009h1 & & \\
\hline Washington & $2007 \mathrm{~h} 2$ & & 2011h2 & 2011h2 & \\
\hline West Virginia & & $2012 \mathrm{~h} 2$ & $2012 \mathrm{~h} 2$ & 2013h2 & 2013h2 \\
\hline Wisconsin & 2010h2 & & 2013h1 & & \\
\hline Wyoming & & & & 2009h2 & \\
\hline
\end{tabular}

This table reports on laws enacted between January 1, 2007 and December 31, 2013. Note that all states besides Missouri and DC have enacted a PDMP by the end of 2013; however, many states (e.g., Alabama) did so prior to our sample period. 
Table 2: Summary Statistics: Beneficiaries

\begin{tabular}{lcc}
\hline \hline & All Medicare & Opioid Takers \\
\cline { 2 - 3 } Share taking opioids & 0.280 & 1.000 \\
Share dually eligible for Medicaid & 0.400 & 0.496 \\
Share entitled to Medicare due to disability & 0.246 & 0.347 \\
Share with cancer & 0.094 & 0.122 \\
Share who die this half-year & 0.025 & 0.033 \\
Number of person X half-years & $13,221,396$ & $3,703,389$ \\
Mean number of half-years observed & 10.871 & 7.078 \\
\hline \hline
\end{tabular}

"All Medicare" are individuals enrolled in Part D and fee-for-service Medicare (not Medicare Advantage). Opioid takers are those filling at least one opioid prescription.

Table 3: Summary Statistics: Outcomes Among Opioid Takers

\begin{tabular}{lccc}
\hline \hline & Mean & Median & $99^{\text {th }}$ percentile \\
\cline { 2 - 4 } Total Days Supply & 85.5814 & 40.0 & 420.0 \\
211+ Days Supply & 0.0889 & & \\
Mean Daily MED & 9.1519 & 1.3 & 158.4 \\
120+ Daily MED & 0.0169 & & \\
Share with Claims Overlapping & 0.0915 & & \\
Number of Prescribers & 1.5854 & 1.0 & 6.0 \\
5+ Prescribers & 0.0229 & & \\
Number of Pharmacies & 1.2457 & 1.0 & 4.0 \\
5+ Pharmacies & 0.0059 & & \\
Excess Share of Claims from OOS Prescriber & 0.0068 & 0.0 & 0.9 \\
Excess Share of Claims from OOS Pharmacy & -0.0343 & 0.0 & 0.5 \\
Number of New Patient Visits & 0.5068 & 0.0 & 4.0 \\
4+ New Patient Visits & 0.0128 & & \\
Share with Opioid Poisoning Incident & 0.0020 & & \\
\hline \hline
\end{tabular}

Outcomes reported for opioid takers sample described in Table 2 "OOS" signifies out-of-state and "MED" signifies morphine equivalent dosage. See text for definition of morphine-equivalent dosage measures, share of claims overlapping, and excess OOS claims. 

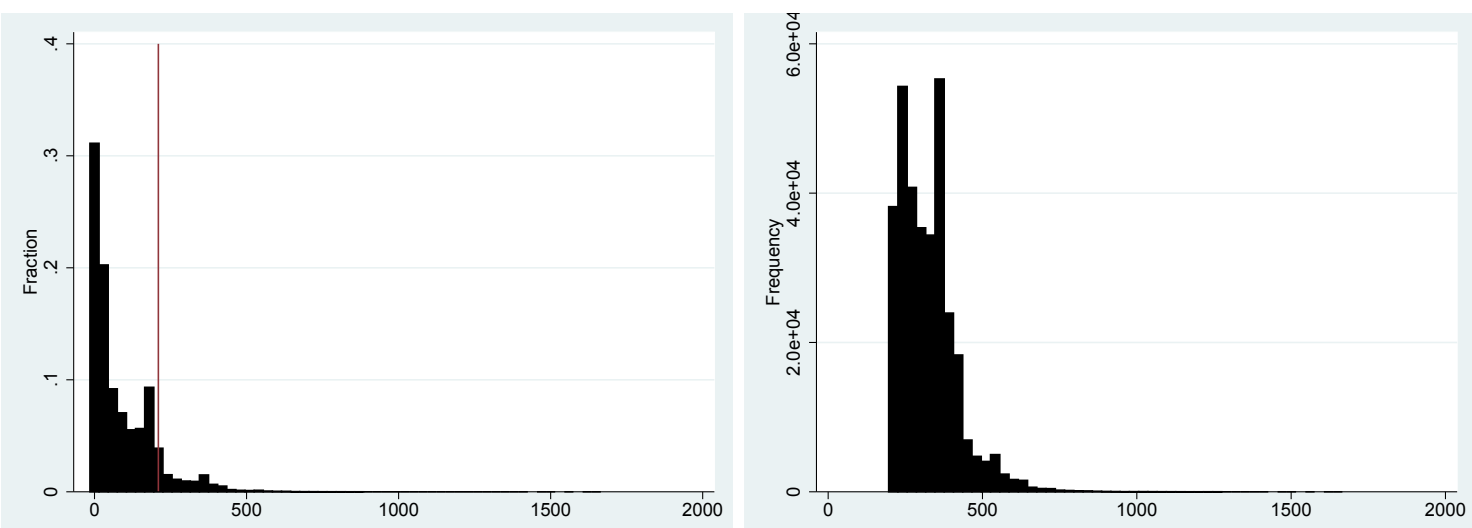

Figure 3: Days supply of opioids in a half-year, each bar=30 days, vertical line at 211 days. Right figure depicts the frequency for only $211+$ days.
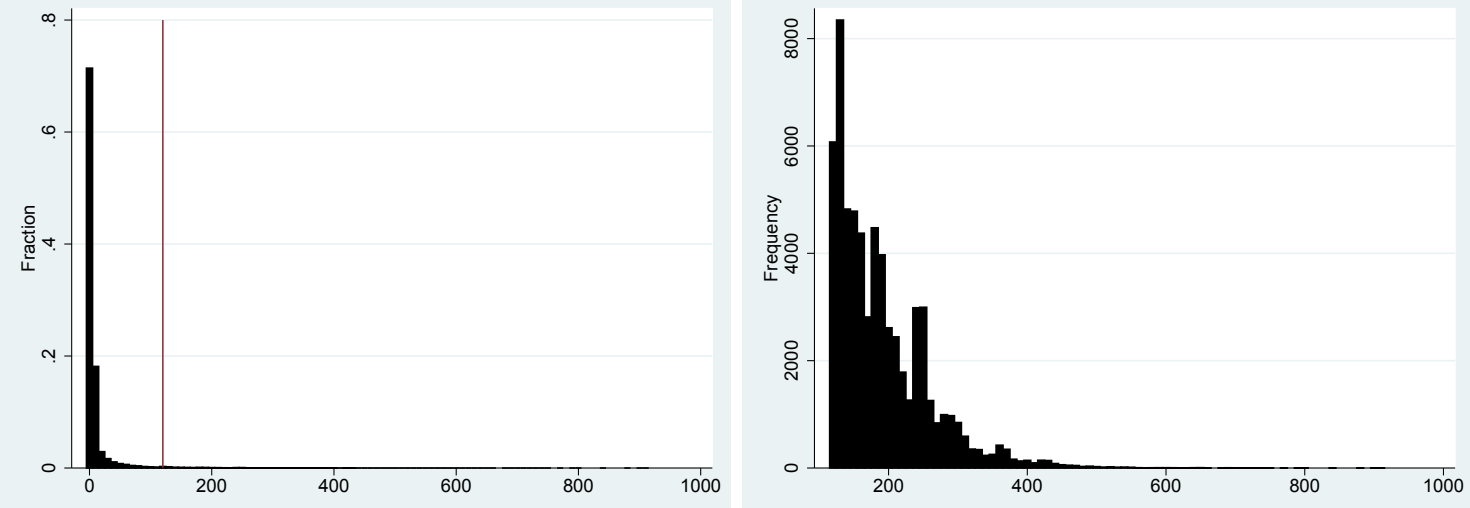

Figure 4: Daily Morphine-Equivalent Dosage obtained in a half-year, each bar=10 daily MED, vertical line at 120 MED each day in the half-year. Right figure depicts the frequency for only $120+$ daily MED.
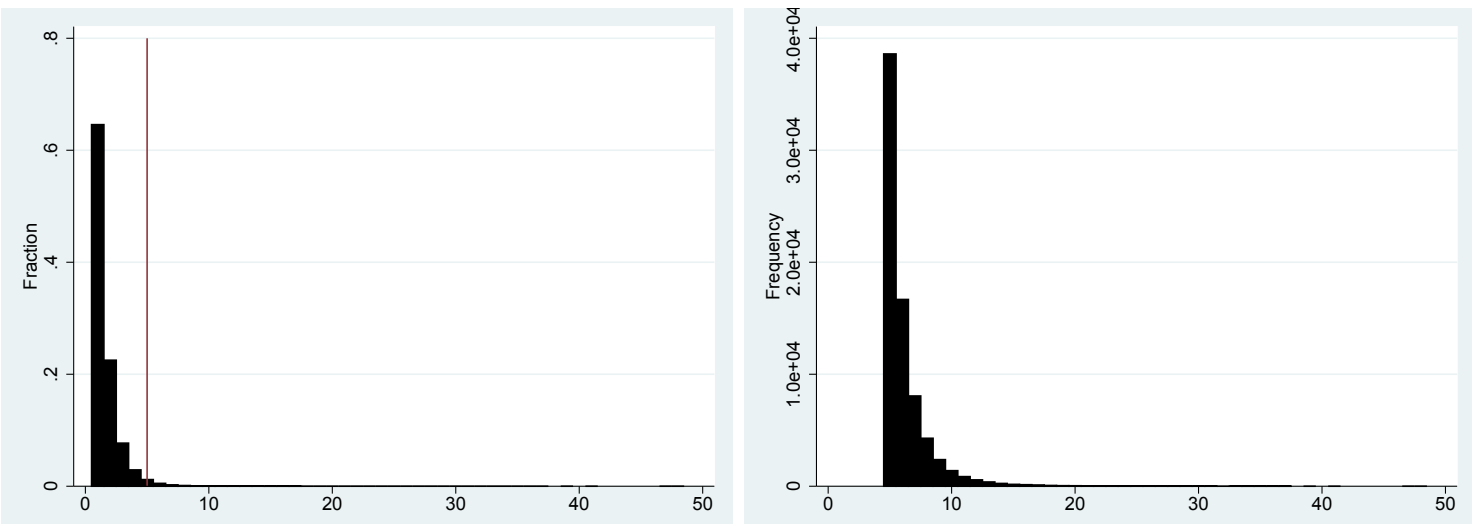

Figure 5: Number of prescribers of opioids, each bar=1, vertical line at 5 prescribers. Right figure depicts the frequency for only $5+$ prescribers. 

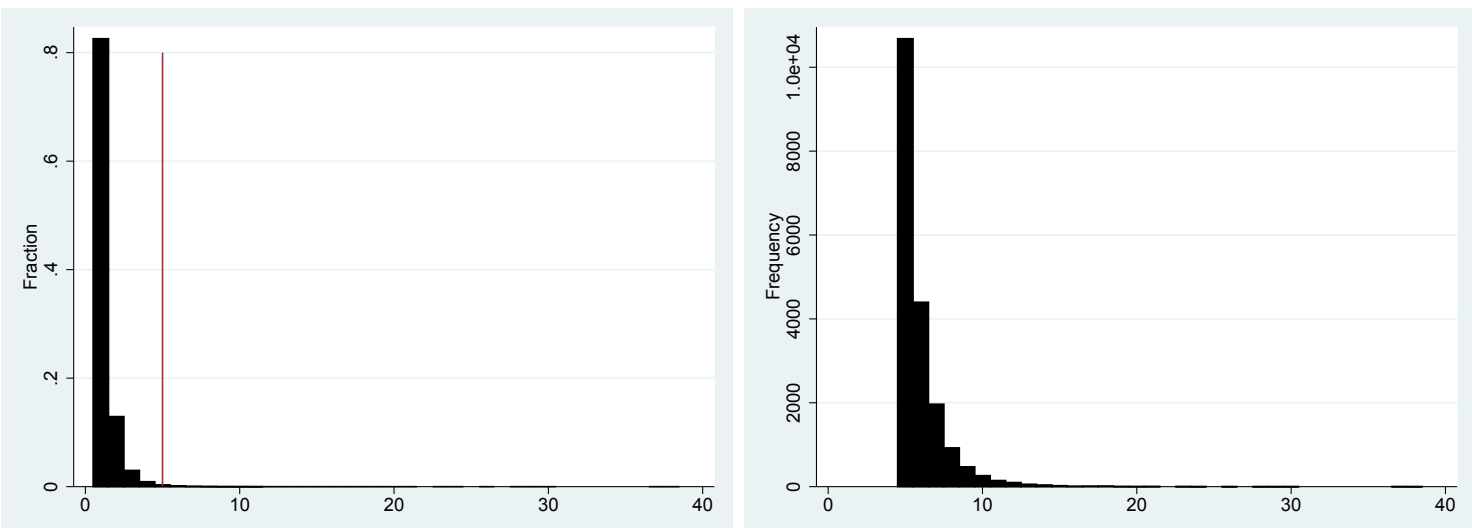

Figure 6: Number of pharmacies for opioids, each bar=1, vertical line at 5 pharmacies. Right figure depicts the frequency for only $5+$ pharmacies.

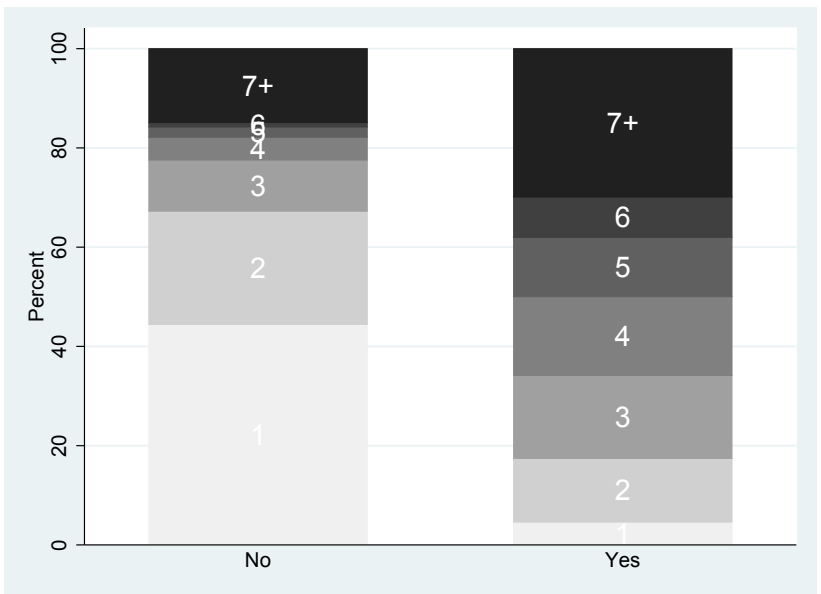

Figure 7: Maximum Number of Prescribers, by Ever Has an Opioid Poisoning Incident

This figure illustrates the distribution of the highest number of prescribers from whom an individual obtains opioids in a half-year, separated by whether the individual ever experiences an opioid poisoning.

Table 4: Correlations Among Measures of Misuse

\begin{tabular}{|c|c|c|c|c|c|c|c|c|c|}
\hline & $(1)$ & $(2)$ & $(3)$ & $(4)$ & $(5)$ & $(6)$ & $(7)$ & $(8)$ & $(9)$ \\
\hline (1) $211+$ Days Supply & 1 & & & & & & & & \\
\hline (2) $120+$ Daily MED & 0.349 & 1 & & & & & & & \\
\hline (3) Overlapping Claims & 0.416 & 0.174 & 1 & & & & & & \\
\hline (4) $5+$ Prescribers & 0.172 & 0.045 & 0.188 & 1 & & & & & \\
\hline (5) $5+$ Pharmacies & 0.147 & 0.054 & 0.131 & 0.291 & 1 & & & & \\
\hline (6) Excess OOS Prescribers & -0.0009 & 0.0007 & -0.004 & 0.006 & 0.004 & 1 & & & \\
\hline (7) Excess OOS Pharmacies & 0.037 & 0.014 & 0.039 & 0.018 & 0.016 & 0.166 & 1 & & \\
\hline (8) $4+$ New Patient Visits & 0.013 & 0.0008 & 0.026 & 0.071 & 0.051 & 0.003 & 0.0009 & 1 & \\
\hline (9) Opioid Poisonings & 0.041 & 0.021 & 0.037 & 0.044 & 0.035 & -0.0001 & 0.005 & 0.006 & 1 \\
\hline
\end{tabular}

Pairwise correlations for measures of misuse and opioid poisoning incidents. Means for each variable available in Tables 2 and 3 . Bold text signifies that the correlation differs from zero at the 0.001 level. 


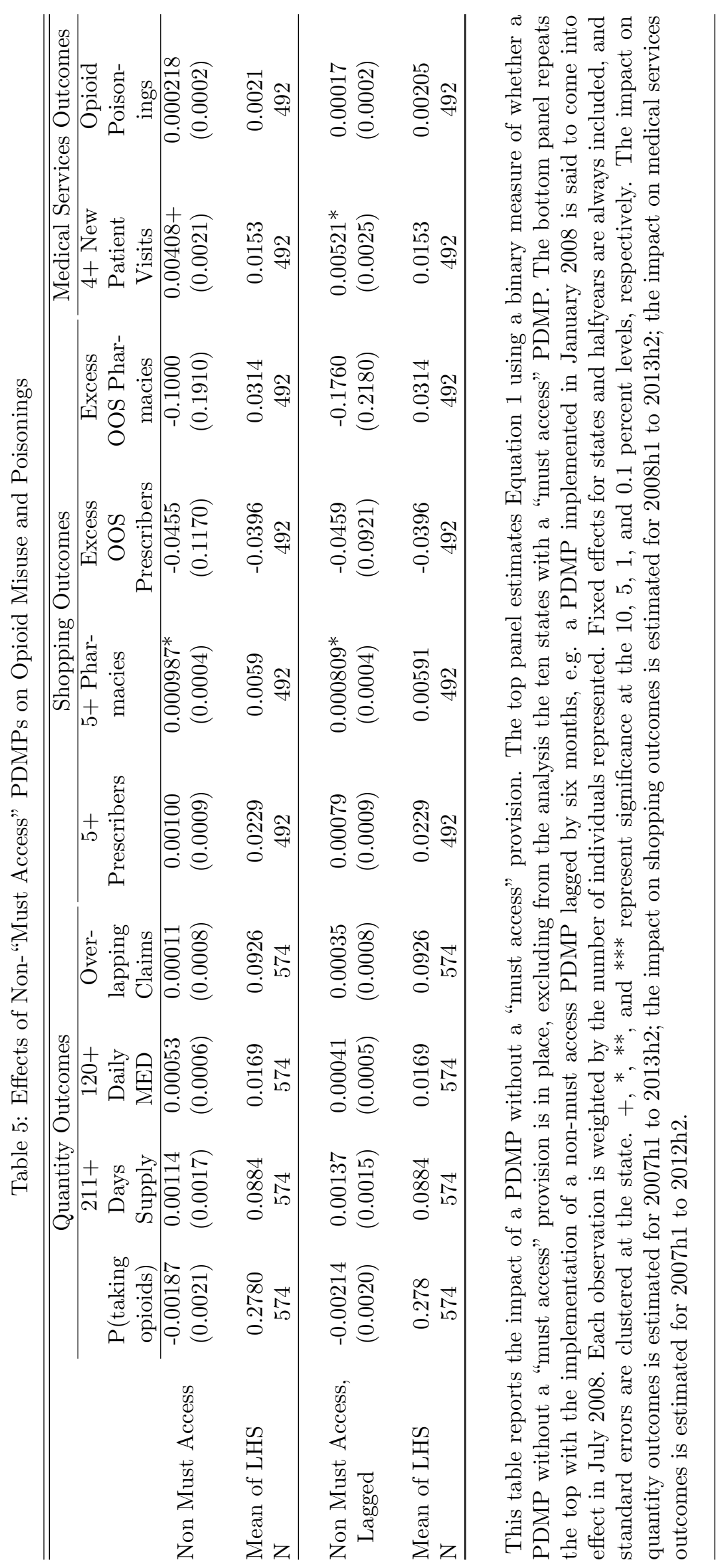




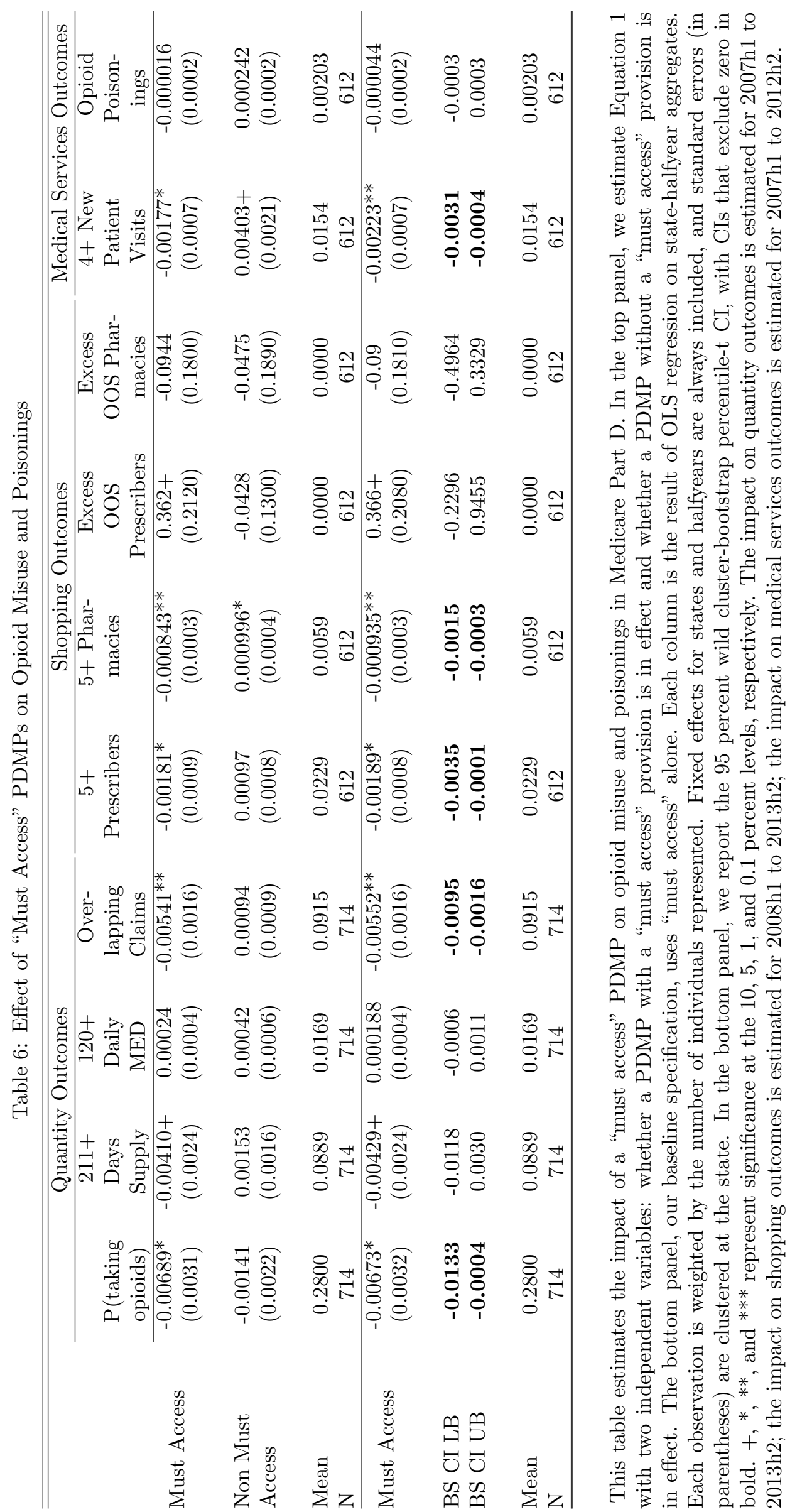



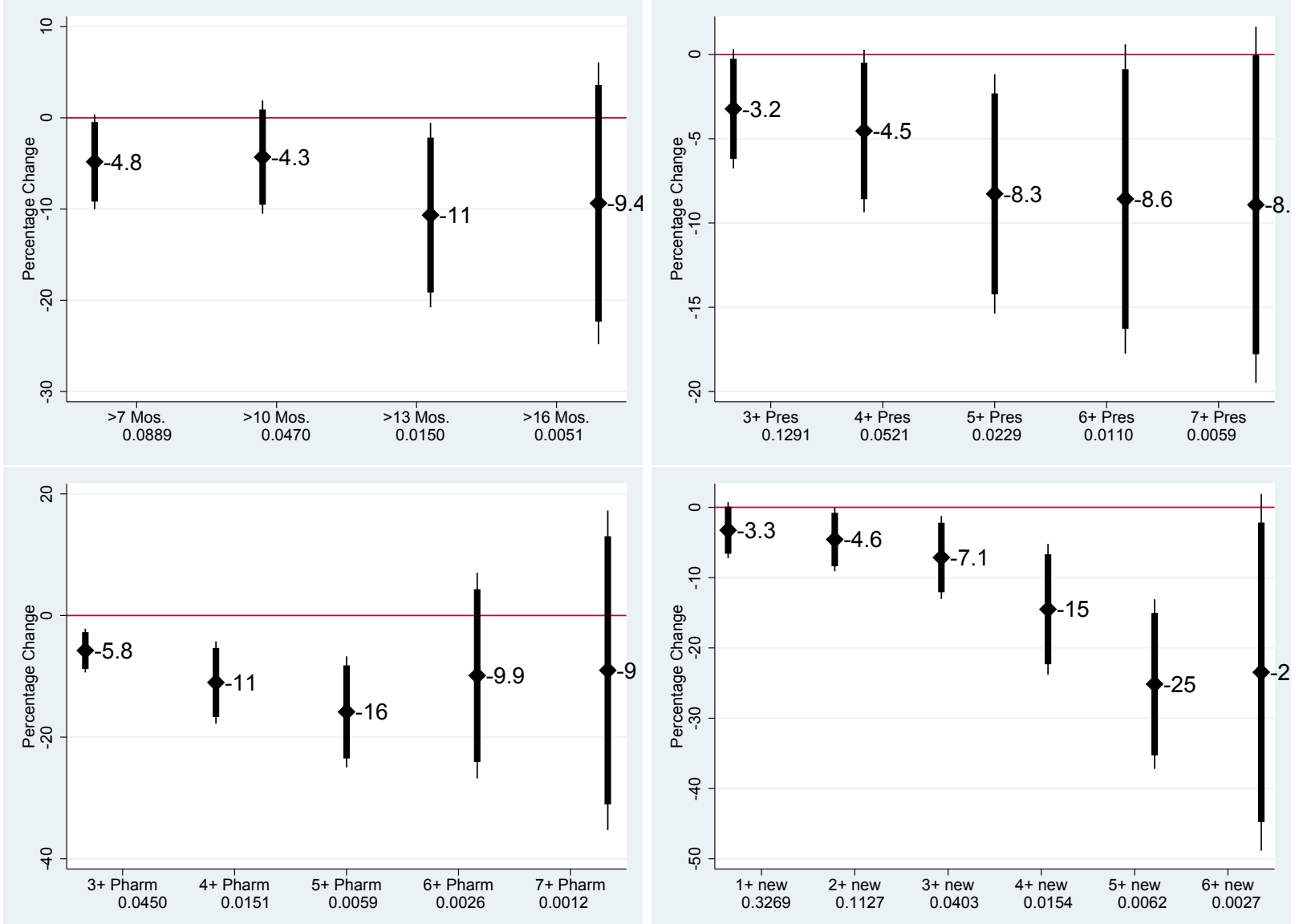

Figure 8: Extremes: Prescribers, Pharmacies, Days Supply, New Patients

These figures extend the analysis reported in Table 6 by sequentially raising the threshold for extreme outcomes for days supply, number of prescribers, number of pharmacies, and new patient visits. The y-axis shows the percentage change that the policy impact of a "must access" PDMP represents as a share of the variable's mean, which is reported along the x-axis. The 95 and 90 percent confidence intervals are depicted by thick and thin bars, respectively. 

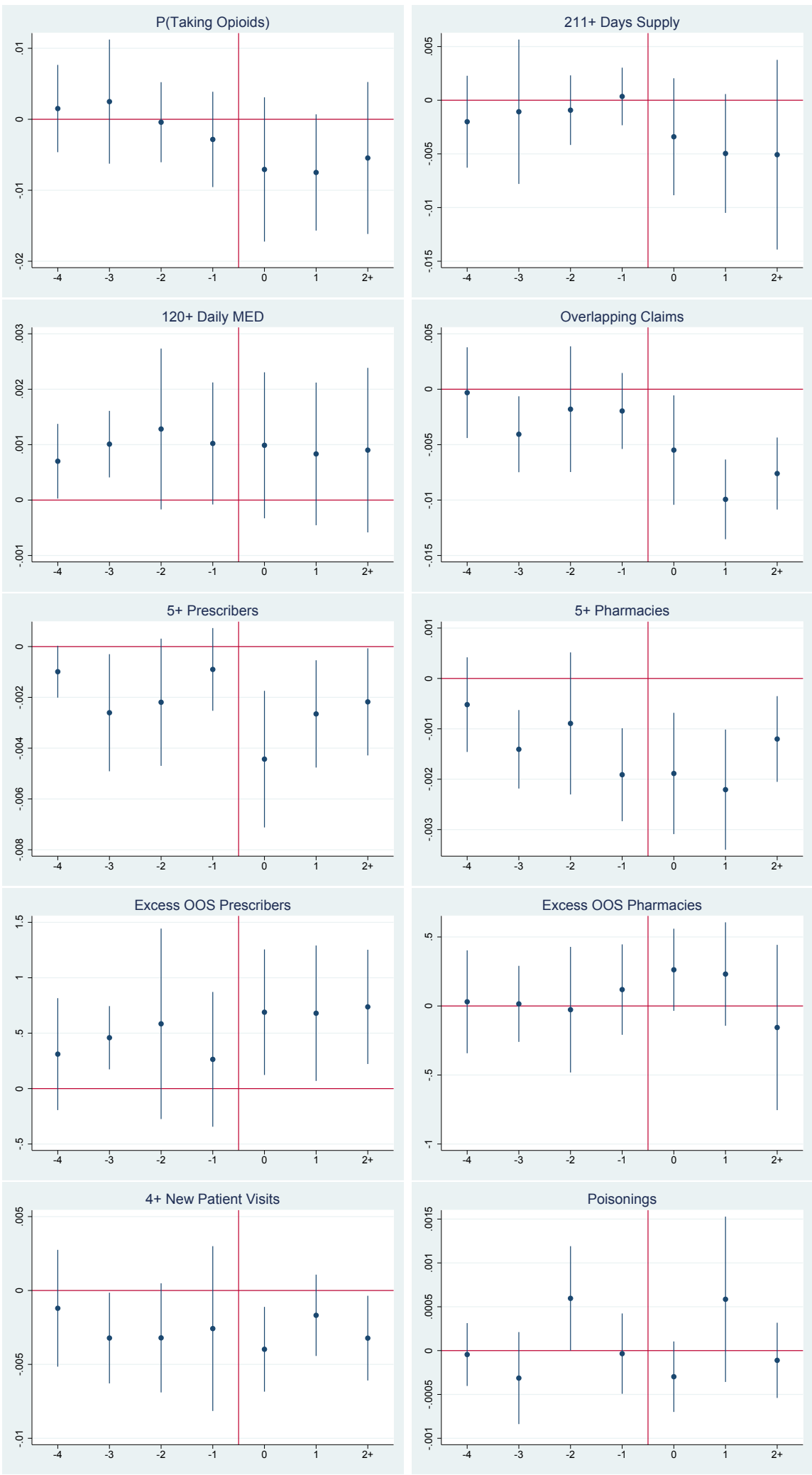

Figure 9: Event Studies; first implementation period is denoted zero

These figures report the estimation of Equation 2, showing the difference between implementation states in the four half-years prior to a "must access" policy and the three half-years following. For each period, we show the point estimate (dot) and its 95 percent confidence interval. 


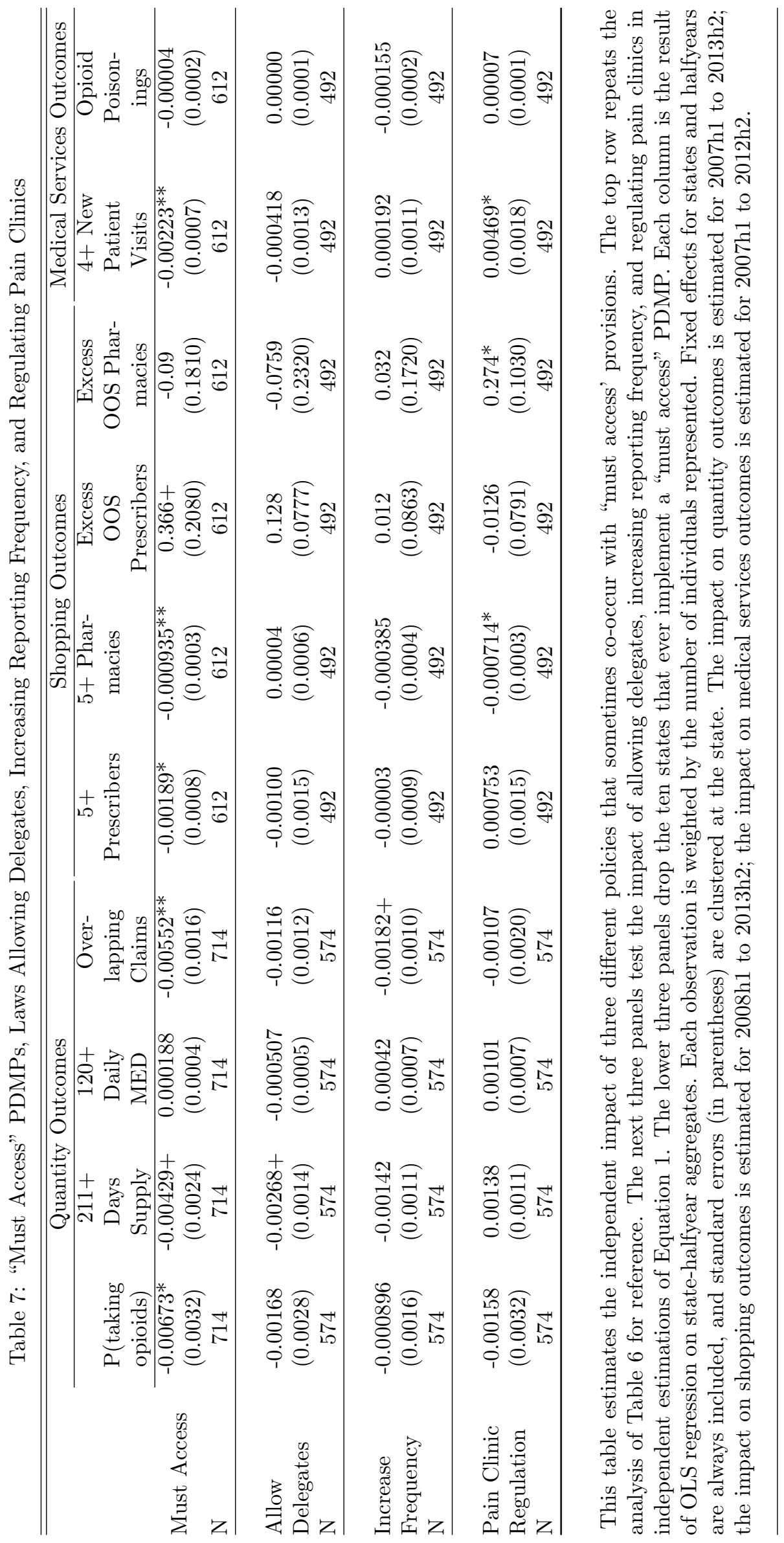



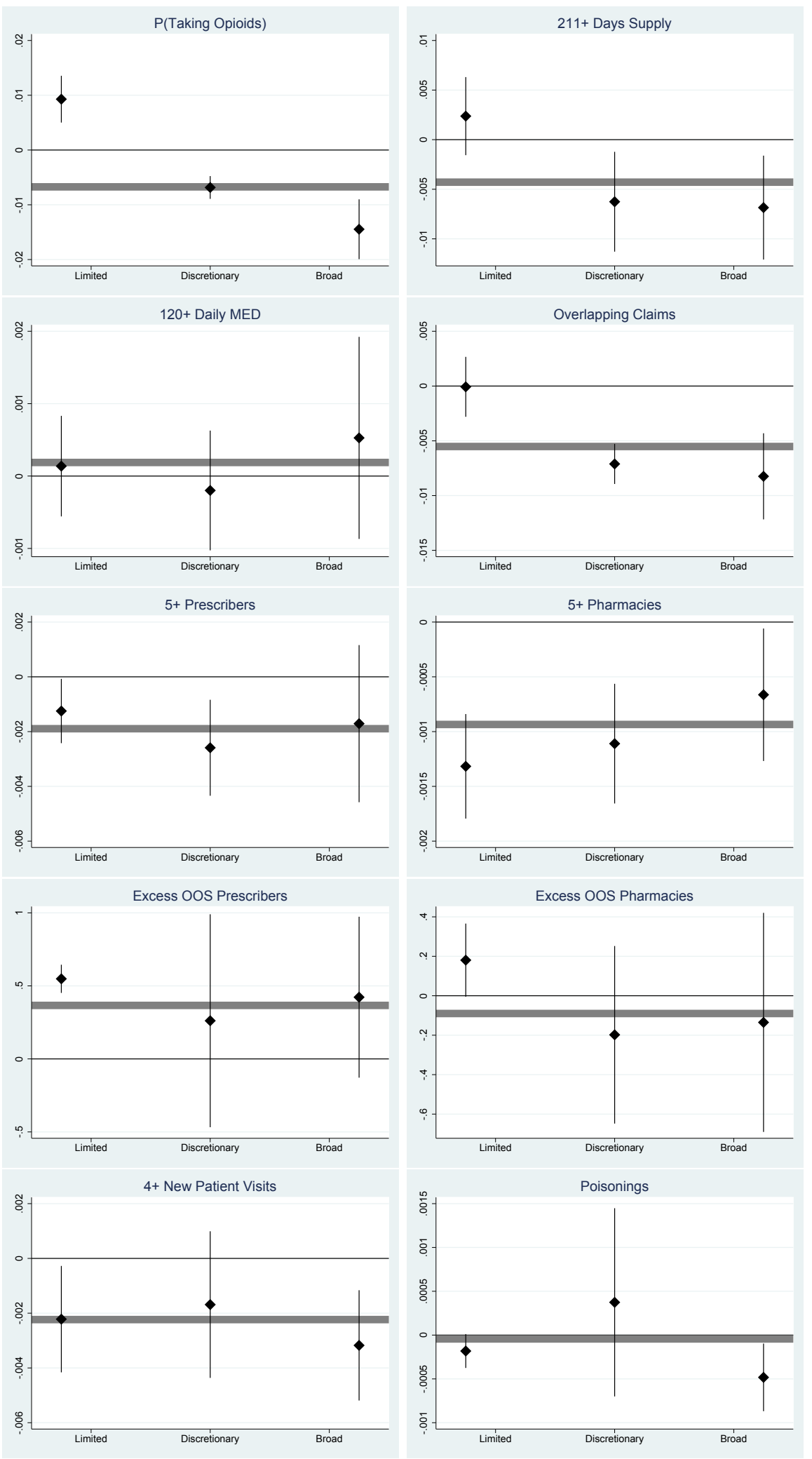

Figure 10: Limited, Discretionary, and Broad Must Access PDMPs.

These figures show how the impact of a "must access" PDMP varies across three subtypes of laws: limited laws that apply to certain ingredients or settings of care, discretionary laws where providers must access the PDMP if suspicious, and broad laws with neither restriction. The figures report the point estimate and 95\% CI from Equation 1 where we include each of the three subtypes as independent variables. Gray bar represents overall estimate from Table 6 . 


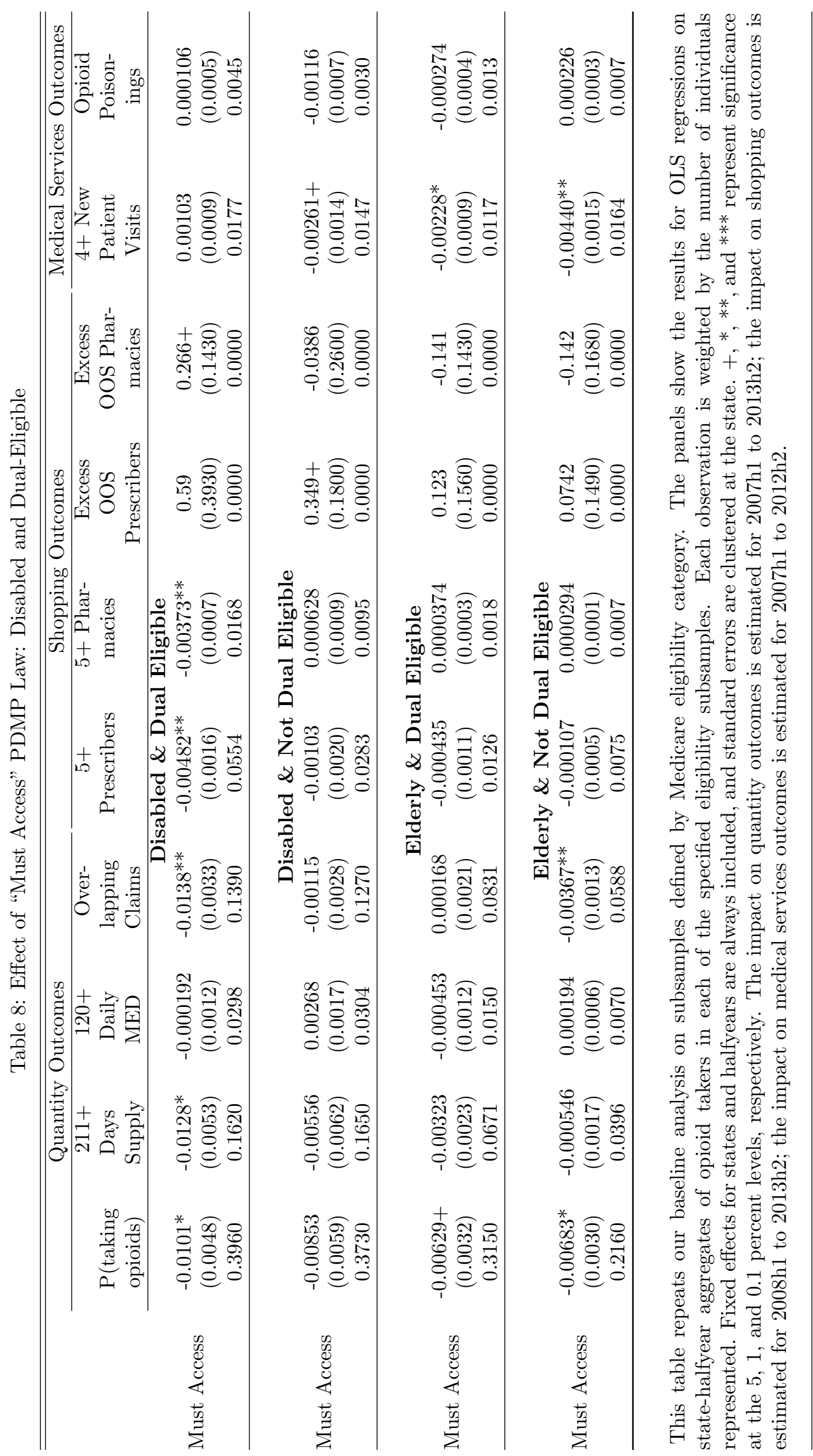




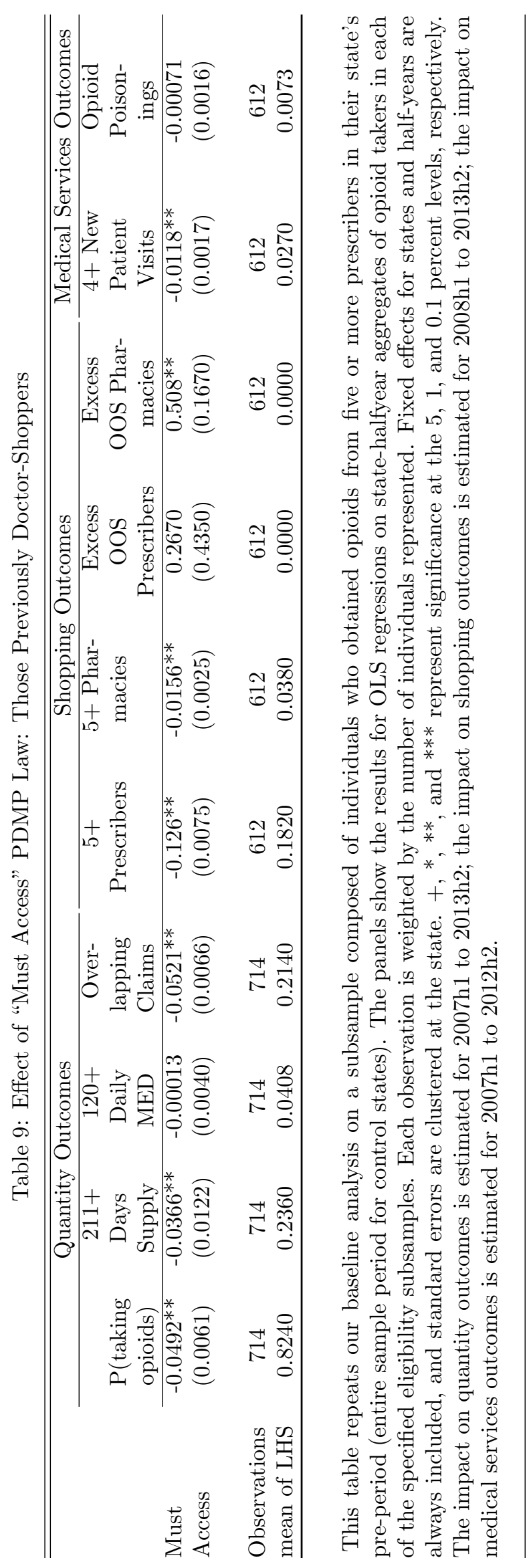









\section{The Effect of Prescription Drug Monitoring Programs on Opioid Utilization in Medicare}

Online Appendix

Thomas Buchmeuller \& Colleen Carey

TBuch@umich.edu \& Colleen.Carey@cornell.edu

\section{Appendix}

\section{A.1 Variable Availability}

Table A.1: Variable Availability

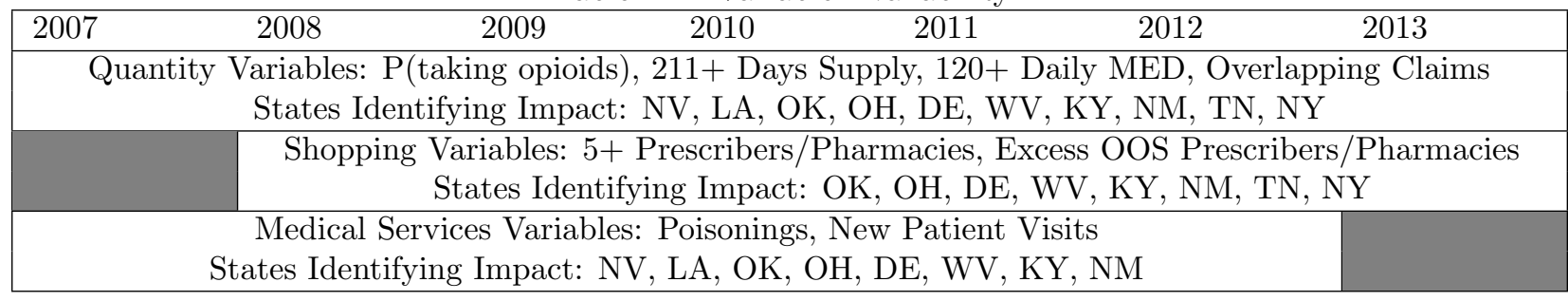

Due to data availability constraints, not all variables studied in this paper are measured over the entire seven year (fourteen half-year) time period covered in this paper. Table A.1 describes the exact availability of our outcome variables. Quantity variables related to taking opioids or days supply are observed in all time periods. Our 2007 Part D Event dataset was from a preliminary release which did not record prescriber or pharmacy; therefore, outcomes related to prescribers or pharmacies are missing for 2007 . We do not have inpatient, outpatient, or carrier medical claims for 2013, so variables calculated from those datasets, such as opioid poisoning incidents or new patient visits, are missing for 2013.

\section{A.2 Supplementary Figures and Tables}




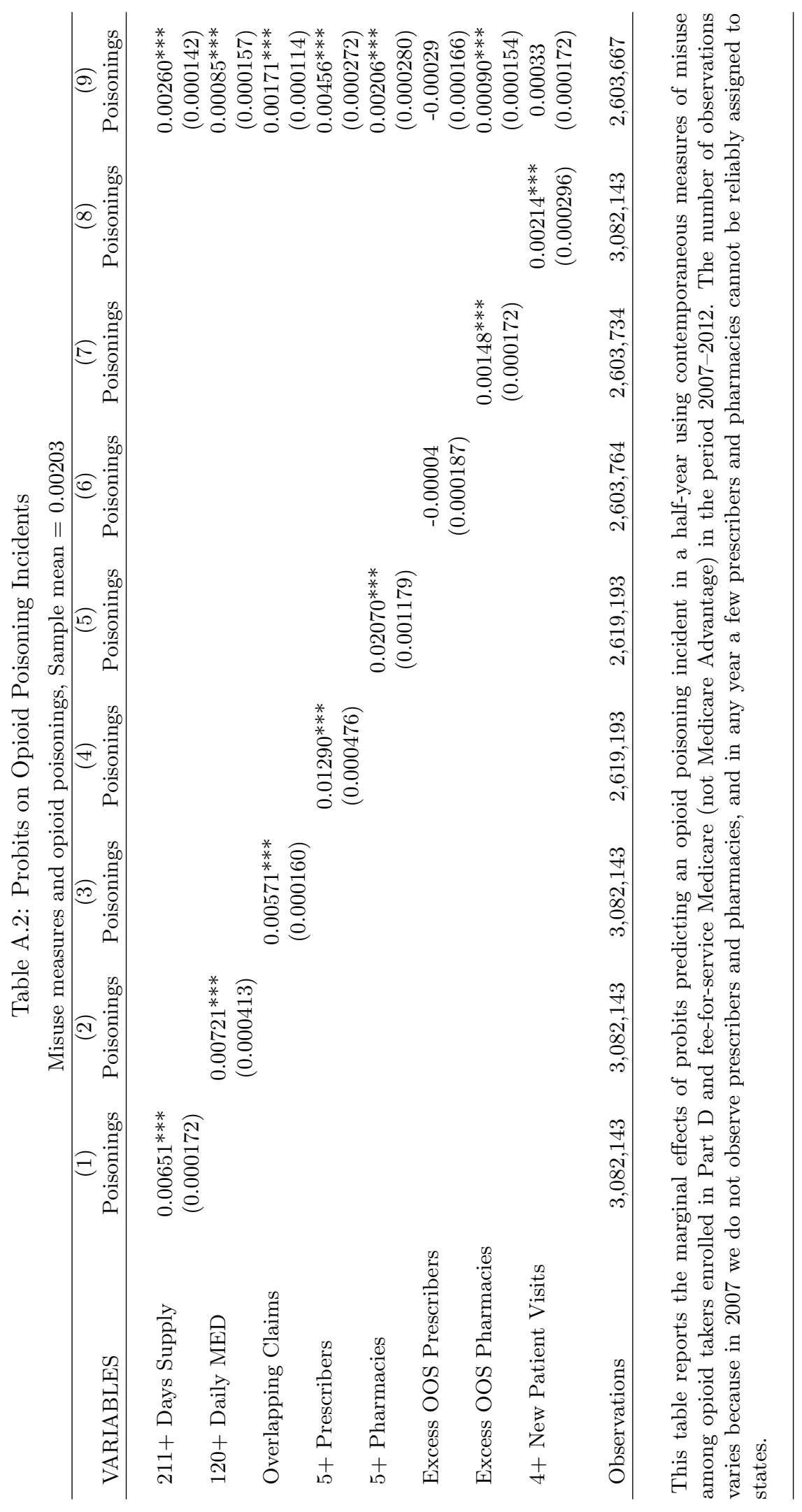




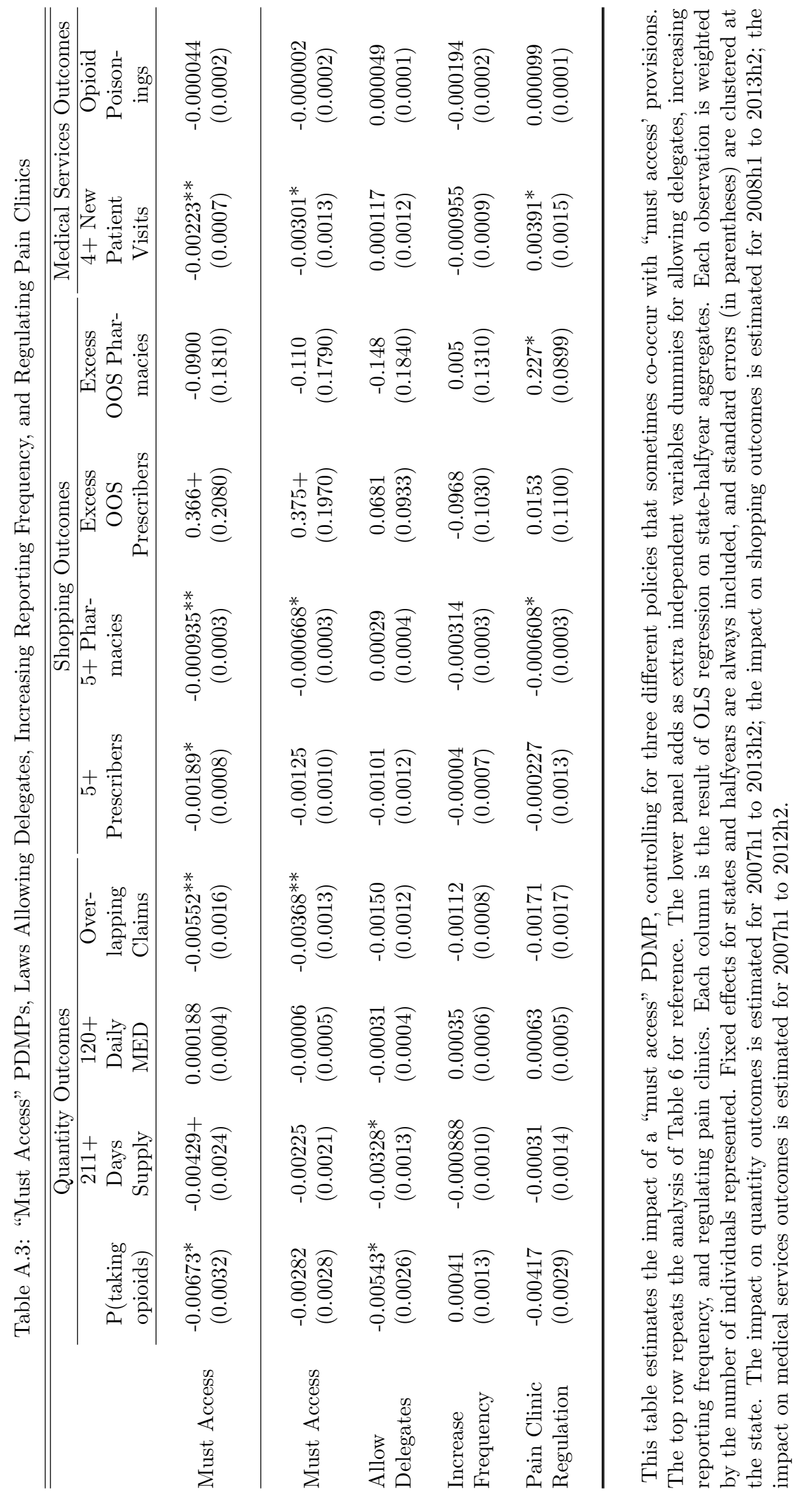



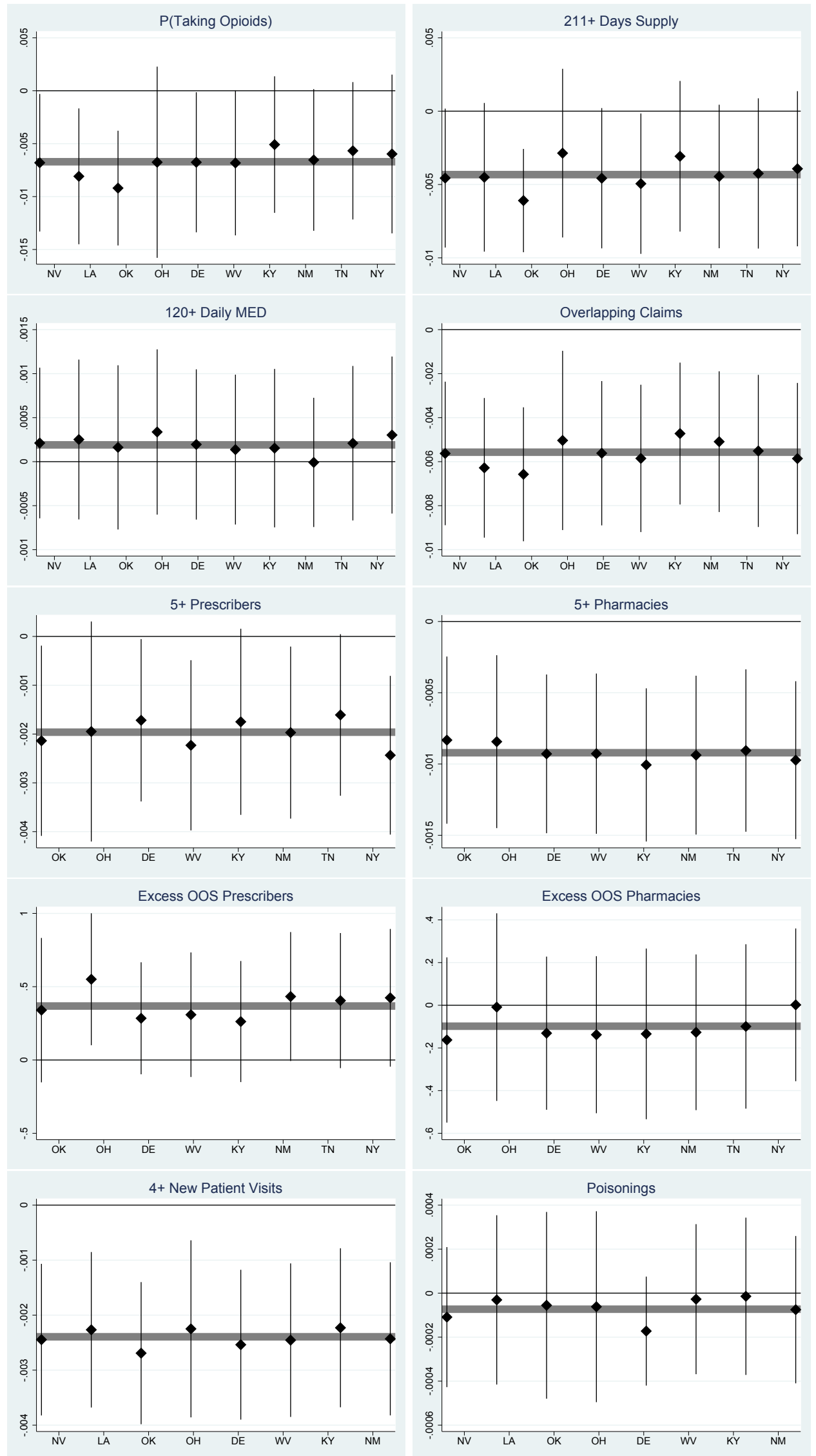

Figure A.1: State-by-State Analysis: Dropping Each State Sequentially. Gray bar denotes overall estimate.

The figures report the point estimate and 95\% CI from Equation 1, where in each regression we drop one state that implements a "must access" PDMP. 


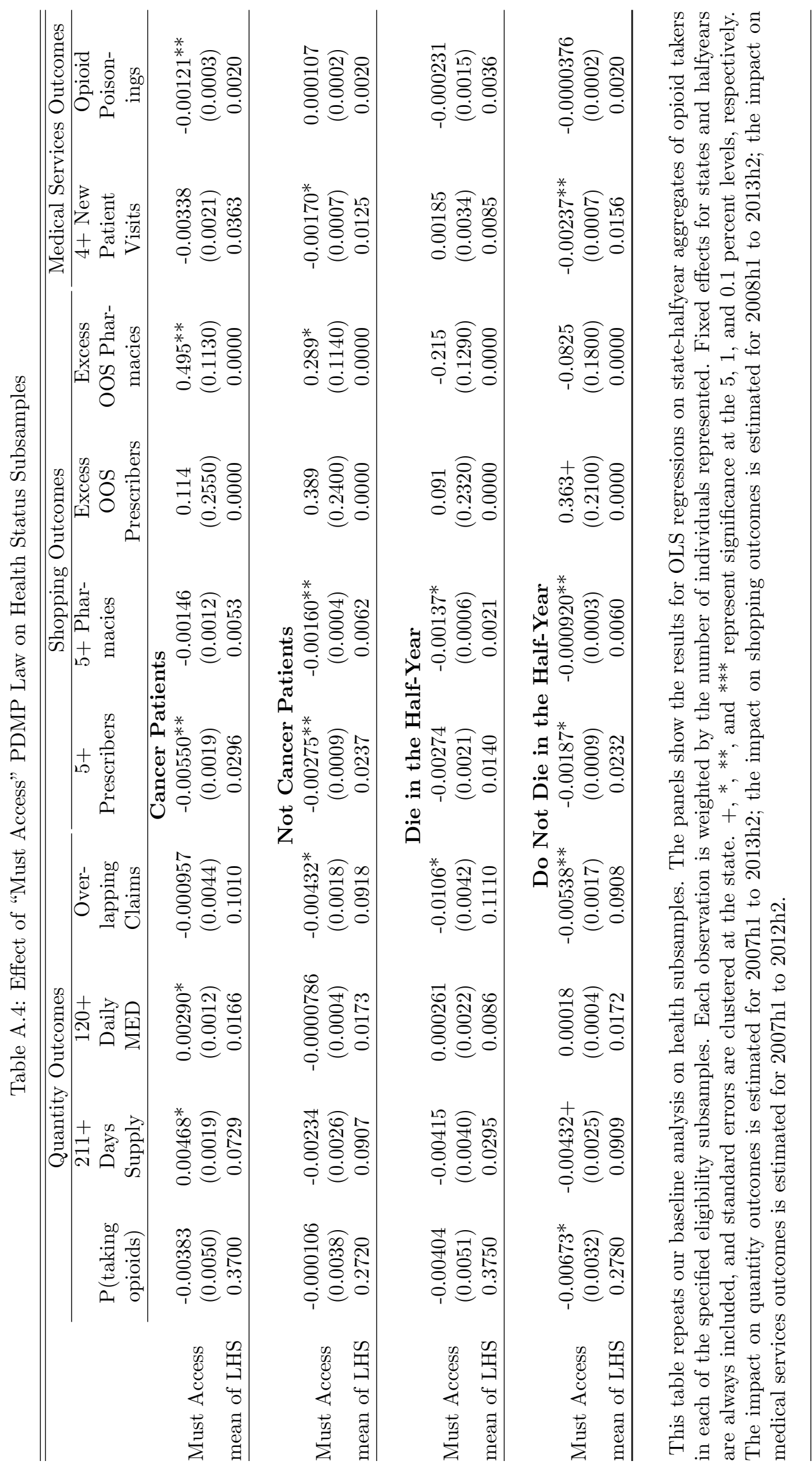

